\title{
A Anastomose do Empreendedorismo Austríaco com Agilidade Organizacional
}

\author{
Andre Barcaui I (D) 0000-0002-7245-4744 \\ Universidade Federal do Rio de Janeiro, Rio de Janeiro, Rio de Janeiro, Brasil
}

Dennys Xavier II (1) 0000-0002-9954-9815

Universidade Federal de Uberlândia, Uberlândia, Minas Gerais, Brasil

\begin{abstract}
Resumo: Este artigo busca fazer uma análise dos conceitos de empreendedorismo na Escola Austríaca através de um formato contemporâneo de gestão denominado "agilidade". O procedimento metodológico adotado foi teórico, com caráter exploratório e descritivo, utilizando uma revisão bibliográfica dos principais autores austríacos e um levantamento bibliométrico das publicações relativas à agilidade. Por meio de uma leitura analítico-interpretativa, procedeu-se a uma análise associativa do empreendedorismo austríaco com agilidade. As conclusões da pesquisa sugerem que, em vários pontos, os autores austríacos se anteciparam às ideias propostas pela agilidade organizacional, especialmente no que tange à preocupação com criação de valor, foco no cliente e adaptação.
\end{abstract}

Palavras-chave: Empreendedorismo, Empreendedor, Ágil, Agilidade Organizacional, Agilidade.

\footnotetext{
I I Pós-doutor em Administração pela FEA/USP, doutor em Administração pela UNR, mestre em Sistemas de Gestão pela UFF-RJ, com graduação em Tecnologia da Informação e Psicologia, com formação em terapia cognitivo-comportamental. Foi project office manager da Hewlett-Packard Consulting, responsável pela região Latino-Americana, e gerente de programa e serviços na IBM. É membro-fundador do PMI Chapter Rio e hoje faz parte do seu Conselho Consultivo. E-mail: barcaui@facc.ufrj.br.

${ }^{\text {II }}$ Doutor em "Storia della Filosofia" pela "Università degli Studi di Macerata" (Bolsista de Doutorado Pleno no Exterior, CAPES, Itália). Tem Pós-doutorado pela Universidade de Coimbra (Bolsista CAPES, Portugal) e Pós-doutorado pela PUC-SP. Tem passagens de pesquisa pela Universidad Carlos III de Madrid, Universidad de Buenos Aires, Trinity College Dublin, Università "La Sapienza" di Roma, Università di Cagliari e Université Paris Sorbonne. E-mail: xavier@mises.org.br.
} 


\title{
The Anastomosis of Austrian Entrepreneurship with Organizational Agility
}

\begin{abstract}
This paper seeks to analyze the concepts of entrepreneurship at the Austrian School under the lens of a contemporary management format called "agility." The methodological procedure adopted was theoretical, with an exploratory and descriptive character using a bibliographic review of the leading Austrian authors and a bibliometric survey of publications related to agility. From an analytical-interpretative reading, it did an associative analysis of Austrian entrepreneurship with agility. The research findings suggest that the Austrian authors at several points anticipated the ideas proposed by business agility, particularly concerning value creation, customer focus, and adaptation.
\end{abstract}

Keywords: Entrepreneurship, Entrepreneur, Agile, Business Agility, Agility.

\section{La anastomosis del Emprendimiento Austriaco con Agilidad Organizacional}

Resumen: Este artículo busca analizar los conceptos de emprendimiento en la Escuela Austriaca bajo la óptica de un formato de gestión contemporáneo llamado "agilidad". El procedimiento metodológico adoptado fue teórico, con carácter exploratorio y descriptivo, haciendo uso de una revisión bibliográfica de los principales autores austriacos y un relevamiento bibliométrico de publicaciones relacionadas con la agilidad. Por medio de una lectura analítico-interpretativa, se realizó un análisis asociativo del emprendimiento austriaco con agilidad. Los hallazgos de la investigación sugieren que los autores austriacos en varios puntos se anticiparon a las ideas propuestas por la agilidad organizacional, particularmente en lo que respecta a la preocupación por la creación de valor, el enfoque al cliente y la adaptación.

Palabras clave: emprendimiento, emprendedor, ágil, agilidad empresarial, agilidad. 


\section{Introdução}

Os padrões de velocidade, capilaridade e impacto das mudanças que o mundo vem experimentando não apresentam precedentes em nossa história (BALOG, 2020; ANTONACOPOULOU, 2018; KHURANA, 2017). Tudo indica que o século XXI vai continuar a ser caracterizado por desafios caóticos, transformacionais e de rápida mudança (WHETTEN; CAMERON, 2007). Nesse Zeitgeist desafiador, o empreendedorismo surge como opção natural para sobrevivência, desenvolvimento e manutenção de novas formas da ação humana (MISES, 2010a). Entretanto, como a atividade empreendedora é reconhecidamente produto do tempo e do contexto em que o empreendedor se enquadra (JULIEN, 2010; BRUYAT; JULIEN, 2001), sua acomodação no chamado mundo VUCA ${ }^{1}$ parece não só indelével como também desejável.

Nesse intrincado contexto, a geração de valor ganha um protagonismo axiomático para o cliente e para a economia como um todo, que é justamente o que enfatiza a Escola Austríaca (MISES, 2010a). Ocorre que uma vez que só os próprios consumidores podem definir o que é valor, dado que sua experiência é subjetiva (MENGER, 2017; MISES, 2010a; LACHMANN, 2007), o desafio se torna portentoso.

Um novo paradigma de gestão, denominado "agilidade", "agilidade nos negócios" ou "agilidade organizacional" ${ }^{2}$, manifesta-se como possível alternativa de amálgama entre essa árdua realidade de mercado e os preceitos do empreendedorismo da Escola Austríaca. A tomada de consciência ou mesmo a homologação do conhecimento desses pontos de intersecção entre a teoria austríaca do empreendedorismo e a agilidade pode ajudar a amenizar o grau de complexidade e mesmo de ansiedade da atitude empreendedora, que é normalmente elevada, em função de sua característica dinâmica.

Este artigo parte justamente desse argumento para desenredar se existem pontos em comum entre a teoria austríaca relacionada ao empreendedorismo e as principais peculiaridades incorporadas pelo movimento ágil nas organizações. O objetivo foi examinar os conceitos de empreendedorismo na Escola Austríaca sob a lente da agilidade. A hipótese motivadora para esse estudo foi de que esse novo arquétipo gerencial não só é compatível como ratifica alguns dos princípios austríacos associados à atividade empreendedora.

O procedimento metodológico adotado foi de natureza teórica e tem caráter exploratório e descritivo quanto aos seus objetivos, na medida em que, além de viabilizar maior familiaridade com o tema, visa também proporcionar um olhar dialógico sobre as vertentes do problema apresentado (GRAY, 2012). Quanto aos procedimentos operacionais, este trabalho de pesquisa fez uso de uma revisão bibliográfica e, portanto, com emprego de fontes secundárias para seu alicerce.

\footnotetext{
${ }^{1}$ Acrônimo em inglês de volátil, incerto, complexo e ambíguo, criado pelo US Army War College (WHITEMAN, 1998), procurando refletir o estado em que mundo se encontrava após o fim da Guerra Fria.

${ }^{2}$ Para efeito desse artigo as expressões "agilidade organizacional" e "agilidade nos negócios" estão sendo utilizadas de maneira intercambiável.
} 
A revisão foi subdivida em duas partes que correspondem aos objetos desta pesquisa: empreendedorismo e agilidade. Na parte relativa ao empreendedorismo, foi feito um discreto histórico para, posteriormente, enfocar a investigação do tema na perspectiva austríaca propriamente dita. Uma vez que os fundamentos da teoria econômica Austríaca são conhecidos e consolidados, optou-se por privilegiar aqueles autores que mais se destacaram em termos de suas contribuições para o conceito de empreendedorismo (TOMETICH, 2020; IORIO, 2011; CONSTANTINO, 2009; BARBIERI, 2001), conforme representado na linha do tempo da Figura 1.

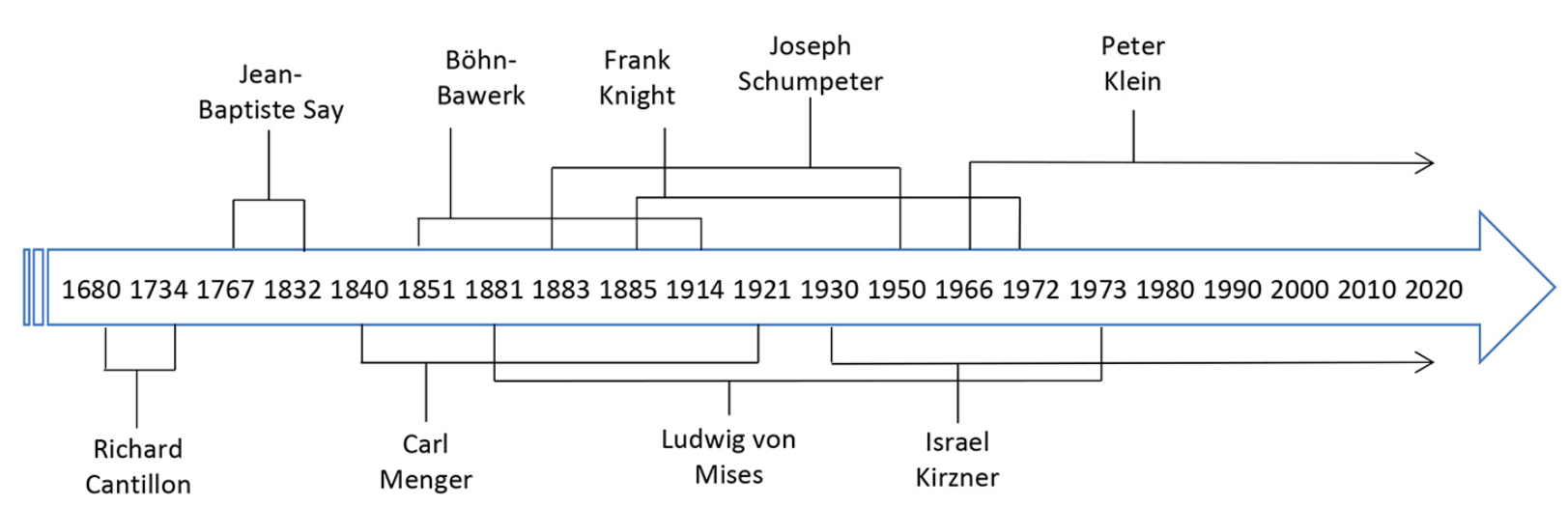

Figura 1. Linha do tempo dos autores austríacos selecionados para pesquisa sobre empreendedorismo Fonte: Autoria própria.

Quanto à agilidade, em se tratando de uma base teórica recente e ainda em construção (BALOG, 2020; RIGBY, et al., 2020; DENNING, 2019; MEYER, 2015), optou-se por um levantamento bibliométrico de artigos relacionados à temática, aspirando compilar e assimilar suas principais características, com vistas à análise a ser efetivada. A busca foi realizada em três bases de dados: Scopus (Elsevier), Science Direct Journal e Emerald Insight. A escolha por essas bases foi feita em função de sua multidisciplinaridade e disponibilidade de conteúdo. As palavraschave utilizadas foram: "ágil", "agilidade", "negócios" e "organização" nos idiomas português e inglês. Dada a pluralidade de possibilidades relativas a essas expressões, optou-se por uma busca que as contivesse diretamente no título, fazendo uso de operadores booleanos.

Cabe ressaltar que a pesquisa ficou restrita a artigos provenientes de periódicos revisados por pares, com corte longitudinal de 2000 a 2020. O levantamento inicial resultou em 267 artigos. A partir desse banco de artigos brutos, foi feita uma averiguação com base nos títulos e no escopo de implantação da agilidade. Os artigos de abordagem essencialmente metodológica ou restritos a departamentos específicos foram retirados da amostra pela não aderência com a faceta desta pesquisa. Aqueles com maior relevância com base em seus resumos, autores com maior número de citações e periódicos compatíveis com o tema foram mantidos, perfazendo um total final de 15 artigos selecionados conforme o Quadro 1 a seguir, organizado em ordem cronológica decrescente. 
Quadro 1. Artigos selecionados pela revisão bibliométrica

\begin{tabular}{|c|c|c|c|c|c|}
\hline Autor & Título & Ano & Periódico & $\begin{array}{c}\mathbf{N}^{\circ} \\
\text { Citações }\end{array}$ & Base \\
\hline $\begin{array}{l}\text { Annosi, M.; } \\
\text { Martini, A.; } \\
\text { Brunetta, F.; } \\
\text { Marchegiani, L. }\end{array}$ & $\begin{array}{l}\text { Learning in an agile setting: a } \\
\text { multilevel research study on } \\
\text { the evolution of organizational } \\
\text { routines }\end{array}$ & 2020 & $\begin{array}{l}\text { Journal of Business } \\
\text { Research }\end{array}$ & 1 & $\begin{array}{l}\text { Science Direct } \\
\text { Journal }\end{array}$ \\
\hline $\begin{array}{l}\text { Ghezzi, A.; } \\
\text { Cavallo, A. }\end{array}$ & $\begin{array}{l}\text { Agile Business Model Innovation } \\
\text { in Digital Entrepreneurship: } \\
\text { Lean Startup Approaches }\end{array}$ & 2020 & $\begin{array}{l}\text { Journal of Business } \\
\text { Research }\end{array}$ & 10 & $\begin{array}{l}\text { Science Direct } \\
\text { Journal }\end{array}$ \\
\hline $\begin{array}{l}\text { Prikladnicki, R.; } \\
\text { Lassenius, C.; } \\
\text { Carver, J. }\end{array}$ & Trends in Agile: Business Agility & 2020 & IEEE Software & 0 & $\begin{array}{l}\text { Scopus } \\
\text { (Elsevier) }\end{array}$ \\
\hline Denning, $S$. & $\begin{array}{l}\text { The quest for genuine business } \\
\text { agility }\end{array}$ & 2019 & $\begin{array}{l}\text { Strategy \& } \\
\text { Leadership }\end{array}$ & 12 & $\begin{array}{l}\text { Emerald } \\
\text { Insight }\end{array}$ \\
\hline Lehn, K. & $\begin{array}{l}\text { Corporate Governance, Agility } \\
\text { and Survival }\end{array}$ & 2018 & $\begin{array}{l}\text { International Journal } \\
\text { of the Economics of } \\
\text { Business }\end{array}$ & 1 & $\begin{array}{l}\text { Scopus } \\
\text { (Elsevier) }\end{array}$ \\
\hline $\begin{array}{l}\text { Rodriguez, D.; } \\
\text { Molina, E.S. }\end{array}$ & $\begin{array}{l}\text { The Experience of } \\
\text { implementation with agile } \\
\text { Business Process Management }\end{array}$ & 2018 & $\begin{array}{l}\text { Advances in Science, } \\
\text { Technology and } \\
\text { Engineering Systems }\end{array}$ & 2 & $\begin{array}{l}\text { Scopus } \\
\text { (Elsevier) }\end{array}$ \\
\hline $\begin{array}{l}\text { Crick, C.; Chew, } \\
\text { E. }\end{array}$ & $\begin{array}{l}\text { Business processes in the agile } \\
\text { organization: a socio-technical } \\
\text { perspective }\end{array}$ & 2017 & $\begin{array}{l}\text { Software and } \\
\text { Systems Modeling }\end{array}$ & 2 & $\begin{array}{l}\text { Science Direct } \\
\text { Journal }\end{array}$ \\
\hline $\begin{array}{l}\text { Chen, R.; } \\
\text { Ravichandar, R.; } \\
\text { Proctor, D. }\end{array}$ & $\begin{array}{l}\text { Managing the transition to the } \\
\text { new agile business and product } \\
\text { development model: Lessons from } \\
\text { Cisco Systems }\end{array}$ & 2016 & Business Horizons & 6 & $\begin{array}{l}\text { Science Direct } \\
\text { Journal }\end{array}$ \\
\hline Denning, S. & $\begin{array}{l}\text { How to make the whole } \\
\text { organization "agile" }\end{array}$ & 2016 & $\begin{array}{l}\text { Strategy } \mathcal{E} \\
\text { Leadership }\end{array}$ & 9 & $\begin{array}{l}\text { Emerald } \\
\text { Insight }\end{array}$ \\
\hline Denning, $S$. & $\begin{array}{l}\text { Agile: it's time to put it to use to } \\
\text { manage business complexity }\end{array}$ & 2015 & $\begin{array}{l}\text { Strategy \& } \\
\text { Leadership }\end{array}$ & 1 & $\begin{array}{l}\text { Emerald } \\
\text { Insight }\end{array}$ \\
\hline Caligiuri, P. & $\begin{array}{l}\text { Developing culturally agile } \\
\text { global business leaders }\end{array}$ & 2013 & $\begin{array}{l}\text { Organizational } \\
\text { Dynamics }\end{array}$ & 10 & $\begin{array}{l}\text { Science Direct } \\
\text { Journal }\end{array}$ \\
\hline $\begin{array}{l}\text { Melarkode, A.; } \\
\text { From-Poulsen, M.; } \\
\text { Warnakulasuriya, } \\
\text { S. }\end{array}$ & Delivering Agility through IT & 2004 & $\begin{array}{l}\text { Business Strategy } \\
\text { Review }\end{array}$ & 9 & $\begin{array}{l}\text { Science Direct } \\
\text { Journal }\end{array}$ \\
\hline Verstraete, C. & $\begin{array}{l}\text { Planning for the unexpected } \\
\text { [business agility] }\end{array}$ & 2004 & $\begin{array}{l}\text { Manufacturing } \\
\text { Engineer }\end{array}$ & 7 & $\begin{array}{l}\text { Science Direct } \\
\text { Journal }\end{array}$ \\
\hline $\begin{array}{l}\text { Wadhwa, S; Rao, } \\
\text { K. }\end{array}$ & $\begin{array}{l}\text { Flexibility and Agility for } \\
\text { Enterprise Synchronization: } \\
\text { Knowledge and Innovation } \\
\text { Management Towards } \\
\text { "Flexagility" }\end{array}$ & 2003 & $\begin{array}{l}\text { Studies in } \\
\text { Informatics and } \\
\text { Control }\end{array}$ & 6 & $\begin{array}{l}\text { Scopus } \\
\text { (Elsevier) }\end{array}$ \\
\hline $\begin{array}{l}\text { Ramasesh, R; } \\
\text { Kulkarni, S; } \\
\text { Jayakumar, M. }\end{array}$ & $\begin{array}{l}\text { Agility in Manufacturing } \\
\text { Systems: an exploratory } \\
\text { modeling framework and } \\
\text { simulation }\end{array}$ & 2001 & $\begin{array}{l}\text { Integrated } \\
\text { manufacturing } \\
\text { systems }\end{array}$ & 5 & $\begin{array}{l}\text { Scopus } \\
\text { (Elsevier) }\end{array}$ \\
\hline
\end{tabular}

Fonte: Autoria própria. 
A partir de uma leitura analítico-interpretativa do empreendedorismo, na visão dos autores da Escola Austríaca, foi realizada uma análise associativa sob a ótica da agilidade organizacional, conforme a Figura 2 a seguir:

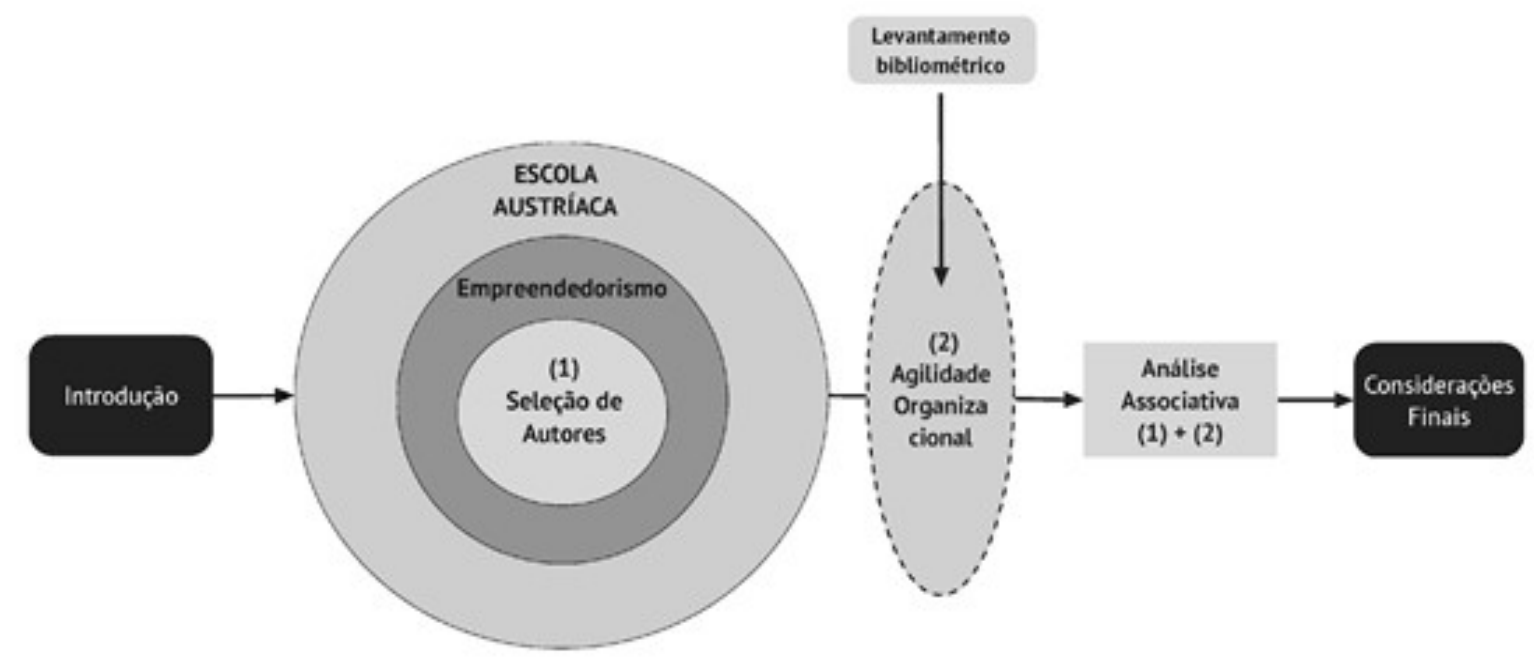

Figura 2. Representação gráfica do procedimento metodológico

Fonte: Autoria própria.

O exame do empreendedorismo na hermenêutica Austríaca sob a lente da agilidade organizacional se justifica em função de sua serventia para pesquisadores, tanto da economia austríaca quanto da gestão de empresas, na medida em que fornece um novo fator de análise ou ponto de partida para um derivativo de sua estrutura, seja para aprimorá-la ou refutála. Além disso, para empreendedores, serve também como base de suporte para deliberar, com maior nível de segurança e conforto, sobre decisões vindouras de negócio, com base na interdisciplinaridade, oriunda da sólida base da economia austríaca e do contemporâneo olhar da agilidade nos negócios.

\section{Empreendedorismo: Origens do Conceito}

Ainda que tenha ganho maior destaque na literatura recentemente (BITTAR et al., 2014; MACHADO; NASSIF, 2014), a história do empreendedorismo remete à Idade Média (HISRICH et al., 2009). Sem embargo, parece haver um consenso na literatura que a expressão "empreendedor" teria sido introduzida no contexto econômico e da gestão principalmente por Jean-Baptiste Say (1767-1832) e Richard Cantillon (1680-1734), ambos influenciados pelo iluminismo. Segundo Iorio (2013), enquanto Adam Smith teria ignorado a figura do empreendedor do pensamento econômico, Say, em função da sua preocupação com o mundo real, teria trazido esse importante personagem de volta à discussão. Favorável ao empreendedorismo como força motora das

\footnotetext{
${ }^{3}$ Do francês: "entrepreneur".
} 
alocações e ajustamentos da economia de mercado, Say entendia que os desejos dos clientes determinariam o que deveria ser produzido (IORIO, 2013).

Segundo Say, o empreendedor organiza e dirige os fatores de produção, o que requer uma combinação de qualidades morais (BARBIERI, 2013). O autor talvez tenha sido o primeiro a definir um leque de funções para o empreendedor, visto que o diferenciou dos capitalistas e o colocou como agente estratégico na coordenação do processo de produção, diferenciando-os daqueles que operam sob incerteza (FILION, 1999; LYNSKEY; SEIICHIRO, 2002).

Todavia, para efeito deste estudo, torna-se indispensável colocar ênfase na perspectiva de Cantillon sobre o empreendedor e seu papel de reflexão sobre as incertezas provocadas pelos riscos da economia (CANTILLON, 2002). Seu posicionamento a respeito do tema foi muito provavelmente motivado por sua própria vida e inicio de carreira, quando exerceu papel de contador e negociador de contratos. Ele comenta sobre o empreendedor no clássico senso do grande desbravador de negócios, mas também estabelece uma distinção teórica entre aqueles que trabalham por um ganho fixo e aqueles que enfrentam retornos incertos, incluindo agricultores, fabricantes, entre outros. São aqueles que compram insumos a um determinado preço para produzir e vender posteriormente a um preço incerto.

Suas contribuições são de tal significância e abrangência, que muitos o consideram como o pai da economia moderna em detrimento ao próprio Adam Smith (BRANDA, 2011), que teria se inspirado em algumas das suas concepções (ROTHBARD, 2009). Foi perspicaz ao desenvolver uma compreensão econômica original sobre bancos, moeda, comércio internacional e mercado de ações, meio através do qual montou sua fortuna (ALDRICH, 2012; LANDSTRÖM; LOHRKE, 2010; BRUYAT; JULIAN, 2001). Realizou a regulação dos mercados em função do movimento dos preços com base na (hoje clássica) teoria da oferta e demanda, identificando uma tendência equilibradora mediante a troca voluntária, conforme um de "Fluxo Circular da Riqueza" (CANTILLON, 2002).

Cantillon apostava em um sistema de mercado sem interferência governamental, verificando que a principal força provocadora de desequilíbrios na economia é a manipulação do dinheiro e dos juros por parte do governo, criando o que se convencionou chamar de "Efeito Cantillon", também chamado "Efeito de Injeção" ou "Efeito de Primeira Ordem" (CARVALHO; NETO, 2019). Ou seja, embora os preços subam conforme a quantidade de dinheiro aumenta, os mesmos não sobem proporcionalmente, mas sim, de uma forma complexa que depende de quem primeiro recebeu o dinheiro e de como ele foi gasto (IORIO, 2014b). Ele forneceu uma teoria convincente dos ciclos dos negócios, na qual os ciclos são causados justamente pela manipulação governamental, que acaba provocando má alocação de capital e uma redistribuição de renda não benéfica à sociedade (THORTON, 2006). A demanda de bens seria o determinante dos preços e não os custos de produção. A função dos custos seria o de informar ao empreendedor se existem benefícios no negócio pretendido. Em outras palavras, a informação econômica perfeita em formato estático não se aplicava.

No esforço de lucrar, o empreendedor deve ser capaz de suportar riscos em função dessa incerteza generalizada inerente ao mercado. Como exemplo, Cantillon (2002, p. 44) cita o agricultor que tem despesas fixas, mas o preço de seus produtos depende em parte 
das condições climáticas e em parte da própria demanda que, se for abundante em relação ao consumo, será barata, mas se houver escassez, será cara. É impossível prever o número de nascimentos e mortes de pessoas em um país ao longo do ano. Da mesma forma, se torna inviável prever o aumento ou redução de despesas das famílias ao longo de um período. Entretanto, o preço dos produtos do agricultor depende naturalmente dessas circunstâncias e, consequentemente, a administração da fazenda é feita sob a égide da incerteza. Dessa forma, o empresário mal sucedido viverá mal ou falirá, enquanto que o empresário de sucesso obterá lucro ou vantagem, e é dessa forma que os empreendedores de todos os tipos se ajustam aos riscos do mercado (THORNTON, 1999).

Com base nesse comedido resumo da teoria de Cantillon é possível notar as razões da sua influência na escola austríaca, além da enorme quantidade de antecipações de conceitos que viriam a ser construídos ou consolidados somente séculos depois, inclusive pelo mainstream ${ }^{4}$. Como colocado por Thornton (1999, p. 13), "sua obra é mais que um mero ensaio, mas sim, um tratado sistemático e conectado, cobrindo, de uma forma concisa, quase todo o campo da economia".

\subsection{Empreendedorismo na Escola Austríaca}

Para a escola Austríaca, a função do lucro está ligada ao valor que adiciona à economia e à sociedade como um todo (MISES, 2010a). De modo análogo, o eventual prejuízo reflete uma destruição de valor. Essa concepção sugere que os empreendedores têm um papel fundamental nessa perspectiva, porque são eles que tentam desbravar oportunidades e agregar valor, por vezes de forma hercúlea, mesmo em cenários hostis ao investimento. São os que assumem os riscos sob condição de incerteza, movidos por um ideal maior, visando lucro e gerando riqueza.

Feito esse preâmbulo, a visão do empreendedor na Escola Austríaca foi se modificando e ganhando novas nuances ao longo do tempo, a partir do seu fundador Carl Menger (1840-1921). Salerno (2008) entende que Menger foi o pioneiro de um método de pesquisa teórico único que serviu de arcabouço para toda Escola Austríaca de economia. Menger (2017) concebia a atividade empreendedora como um processo de transformação de bens de ordem superior em bens de primeira ordem (bens que podem ser utilizados direta e imediatamente para satisfazer necessidades concretas).

Para o autor, a função empreendedora depende e só faz sentido no contexto da propriedade privada e a produção de bens de primeira ordem depende não só dos bens de ordem superior, mas também da utilização de capital e da atividade empresarial. No arranjo dessa atividade, estão incluídos: (a) a informação sobre a situação econômica; b) o cálculo de viabilidade econômica), (c) o ato da vontade, através do qual, bens de ordem superior em condições de intercâmbio comercial desenvolvido ${ }^{5}$ são destinados à determinada produção, d) a supervisão, para que a execução do plano de produção seja a mais econômica possível (MENGER, 2017). Segundo Klein (2008a), o núcleo da economia austríaca, incluindo: análise marginal, estrutura

${ }^{4}$ Expressão que se refere às teorias econômicas predominantemente ensinadas, consideradas ortodoxas.

${ }^{5}$ No qual via de regra se pode trocar um bem econômico por quaisquer outros bens. 
temporal da produção, ação humana, valor subjetivo, entre outros, advém da obra pioneira de Menger. Particularmente no que diz respeito a esse último ponto, o autor desenvolveu a "teoria subjetiva do valor" que versa que o valor é um juízo que as pessoas fazem sobre a importância dos bens de que dispõem (MENGER, 2017).

Mais à frente, seguindo a linha do tempo da economia austríaca, Eugen von Böhm-Bawerk (1851-1914), crítico obstinado do pensamento econômico marxista, postula um uso cada vez mais complexo de processos produtivos, com maior utilização de bens de capital em camadas progressivamente afastadas dos bens de primeira ordem (BARBIERI, 2001). Böhm-Bawerk (1986, p. 38) descreveu o capital como sendo “... o conjunto dos produtos intermediários que surgem nas diversas etapas indiretas que perfazem a via de surgimento indireta". Em outras palavras, o capital é formado pelo conjunto de etapas que compõem o processo produtivo na medida em que o empreendedor faz uso de instrumentos que o auxiliam no processo de produção. O uso desse artifício indireto para atingir determinado objetivo logra uma maior produção com menos trabalho, ainda que fazendo uso de mais tempo ao longo do processo.

Böhm-Bawerk (1959) explicou que a preferência de tempo é um fator universal de opção pela satisfação de desejos mais antes que depois. O conceito de roundaboutness envolve justamente essa característica de sacrificar alguma coisa hoje para ter mais no futuro, ou seja, formar uma poupança. Logo, o processo de produção roundabout ${ }^{6}$ é aquele que apresenta a qualidade em que a produção aumenta porque ocorre uma troca intertemporal no produto (IORIO, 2010). Entretanto, para obtenção de um processo de produção indireto, existem alguns requisitos. Os empreendedores têm que ter uma visão da ação mais lucrativa em meio a todas as disponíveis. Além disso, requer investimento em mais bens de capital e novas tecnologias, o que leva à aceitação de que mais tempo passará até que se torne rentável. Também é preciso ter mais acesso à poupança (suas ou de outros investidores) no longo prazo para seguir adiante.

Esse ponto está relacionado ao que Böhm-Bawerk (1986) denominou de "superidade técnica do presente sobre os bens futuros". Dado que a produção é indireta, ela leva tempo e utiliza o capital gerado para transformar terra e trabalho em produção de fato. Assim, lidando com a incerteza e calculando as alocações de fatores de produção, haveria uma identidade entre o capitalista e o empreendedor, visto que ambos se complementariam. Esse empreendedorcapitalista detém e controla os meios de produção, enfrentando as incertezas do mercado. Com efeito, a propriedade do capital e a tomada de decisão constituem o núcleo da função empresarial (BÖHM-BAWERK, 1959).

Vale mencionar também um autor não austríaco, Frank Knight (1885-1972), que através de sua obra, contribuiu diretamente para o entendimento das incertezas e dos riscos com que o empreendedor opera para tentar lucrar no seu negócio. Knight define risco como uma situação em que é possível determinar a probabilidade de sua ocorrência e, portanto, viabilizando um seguro contra a mesma. Já com a incerteza, isso não seria factível (KNIGHT, 1921).

O autor aprimora as ideias Cantillon e Say quando ratifica o papel do empreendedor como agente estratégico cercado de incertezas, que afetam seu julgamento subjetivo de iniciar ou

${ }^{6}$ Indireto: tradução livre. 
não um novo negócio. Além disso, para Knight (1921), os gestores que não possuíssem parcela significativa da empresa tenderiam a ser mais avessos ao risco e sem os bens de capital, no conceito de Knight, não seriam empreendedores (FOSS; KLEIN, 2005).

Considerado o expoente central da Escola Austríaca, Ludwig von Mises (1881-1973) foi conselheiro econômico do governo austríaco na Câmara de Comércio de Viena, lecionou na Universidade de Viena, mas teve que mudar com a família para Genebra e, posteriormente, para os Estados Unidos, em função da perseguição do Nazismo. Mises aprimorou as ideias de Menger, principalmente no que se refere à teoria econômica do dinheiro, trazendo uma explicação sobre a precificação das unidades monetárias com base na teoria do valor subjetivo (MURPHY, 2010).

O autor alicerçou sua epistemologia no princípio da praxeologia ${ }^{7}$, demonstrando que o conhecimento econômico deveria ser fundamentado menos em constantes matemáticas e mais na tríade ação-tempo-conhecimento (IORIO, 2011). Ponto igualmente ressaltado por Hayek (1945) quando comenta da insuficiência e dispersão do conhecimento social entre as pessoas. Conhecimento este que é tácito, subjetivo e, portanto, de difícil transmissão. Para Mises (2012), a ação humana seria o primeiro axioma praxeológico, do qual advém as leis comportamentais que governam a economia. O tempo é dinâmico, mobilizando um fluxo perene de novas experiências e o conhecimento possui componentes de imprevisibilidade, o que faz com que as ações humanas produzam efeitos involuntários impossíveis de serem calculados por dedução (IORIO, 2011). Como resultante também dessa tríade, temos que o mercado é movido pelas ações de seus agentes, seja na demanda ou na oferta, logo apresenta característica volátil ao longo do tempo.

(...) As atividades do empreendedor consistem em tomar decisões. Ele determina com que propósito os fatores de produção devem ser empregados. Quaisquer outros atos que ele porventura efetue são meramente secundários à sua função empreendedorial. (...) Há uma simples regra prática para se distinguir empreendedores de não-empreendedores. Os empreendedores são aqueles sobre quem recai a incidência de prejuízos sobre o capital empregado. (MISES, 2012, s/p)

Nesse sentido, o próprio valor não é uma variável estática. Sua eclosão está intimamente ligada a essa questão da preferência temporal, explicitando que a ação humana ocorre no enredo desse mercado em tempo dinâmico, gerando oportunidades constantes de aprendizagem, mas com todas as transações sendo realizadas em condições de conhecimento absolutamente estrito e disperso (IORIO, 2011). A energia ativa dos mercados e que promove inovação são os empreendedores (MISES, 2010a). Porém, dada sua característica completamente dinâmica, o mercado sofre mudanças em seus dados constantemente, forçando um processo de ajuste que pode levar mais ou menos tempo. Cabe ao empreendedor antecipar não somente a direção, mas também a razão do ajustamento para a nova realidade que se descortina continuamente (MISES, 2010a).

\footnotetext{
${ }^{7}$ Termo utilizado por Mises para representar a ciência que estuda as implicações lógicas do conceito da ação humana.
} 
Dessa maneira, empreender simboliza uma ação, uma atitude, que inclusive independe de estar ou não atrelada a um novo negócio. Poder-se-ia agir de forma empreendedora mesmo sendo colaborador de uma empresa ou, até mesmo, na vida pessoal. Portanto, toda ação contém uma boa dose de empreendedorismo e a ação teleológica ${ }^{8}$ busca minimizar incertezas, em face ao resultado causal das ações.

Outro ponto significativo que aparece em Mises (2010b) é a relação entre risco e lucro. $\mathrm{O}$ autor entendia que o empreendedor não colocaria sua segurança material em risco, salvo possuir a convicção de que seus planos são consistentes. Para Mises (2010a), uma das categorias praxeológicas é justamente a dos empreendedores em relação aos lucros ou prejuízos obtidos. As outras categorias seriam: os trabalhadores visando salários, os proprietários de terra visando renda e os capitalistas visando juros. Nesse contexto da análise de lucros e prejuízos, o autor observou que, na impossibilidade da propriedade privada, os mercados simplesmente não poderiam existir. Sem mercados, não há formação real de preços que, por sua vez, formam a base para o cálculo econômico. Sem a devida racionalidade econômica, não é possível calcular lucros e perdas, se tornando quase impossível fazer um atendimento ótimo de qualquer demanda, aumentando a escassez e o desperdício.

O economista e cientista político austríaco Joseph Schumpeter (1883-1950) é um dos autores normalmente citado como um dos mais influentes no que concerne ao tema empreendedorismo (MEHMOOD et al., 2019; BITTAR et al., 2014; MARTES, 2010; BARBIERI, 2001). Foi contemporâneo a Mises e participou de seminários celebrados por Böhm-Bawerk (ABREU, 2012). Mesmo não sendo um membro da Escola Austríaca de pensamento econômico, a essência da sua teoria no que diz respeito à inovação se faz consoante com o tema de pesquisa deste trabalho.

Novas combinações surgiriam da estrutura econômica a partir de dentro, destruindo o antigo e criando o novo. O desequilíbrio provocado pelo novo, posteriormente seria imitado, fazendo com que o sistema voltasse ao estado de equilíbrio (SCHUMPETER, 1961). O empreendedorismo substituiria o ideal de Pareto $^{9}$ de hoje pelas coisas novas diferentes de amanhã. Segundo o autor:

A função do empreendedor é reformar ou revolucionar o sistema de produção através do uso de uma invenção ou, de maneira mais geral, de uma nova possibilidade tecnológica para a produção de uma nova mercadoria ou para a fabricação de uma antiga em forma moderna, por meio da abertura de novas fontes de suprimento de materiais, novos canais de distribuição, reorganização da indústria, e assim por diante. (SCHUMPETER, 1961, p. 166)

Efetivamente, a visão da Escola Austríaca vai na direção contrária à abordagem Schumpteriana (MCCAFFREY, 2014; ABREU, 2012), uma vez que não existiria atividade econômica sem a variável tempo. Os empreendedores e todos os demais agentes deveriam incluir considerações sobre essa variável em seu processo de decisão, dado que o mercado é um

\footnotetext{
${ }^{8} \mathrm{Na}$ obra de Mises, a teleologia é o que pressupõe a ação como um comportamento deliberado causado pela existência de fins subjetivos.

${ }^{9}$ Distribuição ideal de bens entre os consumidores; uma alocação ideal técnica de recursos e quantidades ideais de produção (BRUE, 2006, p. 394).
} 
processo contínuo e mutável de descobertas, sujeito a uma série de diferentes contingências. Essa interação é dinâmica ao longo do tempo, o que torna ainda mais difícil qualquer tipo de previsão a seu respeito. Ainda que tenda ao equilíbrio, não chega a lográ-lo, dado que o estado de equilíbrio é incompatível com os conceitos de incerteza genuína e de tempo real. É o que Hayek denominou de "ordem espontânea" (HAYEK, 1995), que surge da interação entre os indivíduos, cada qual baseado em seus próprios planos e conhecimentos.

O economista britânico Israel Kirzner, que foi orientado em sua tese de doutorado por Mises, referindo-se explicitamente ao mestre, parte do princípio de que o mercado não é um fenômeno estático, mas sim, um processo efetivamente dinâmico e nunca em equilíbrio, onde o empreendedor atua como parte integrante do sistema, e não como destruidor de um suposto equilíbrio (GIANTURCO, 2014). O autor é fulcral para o tema empreendedorismo, considerandose que a literatura a respeito se multiplicou após suas contribuições (GIANTURCO, 2014).

Kirzner (2007) argumenta que o empreendedor puro não é dono dos meios de produção, não tem capital, não tem fatores de produção e não tem recursos em geral. Todavia, compreende e suporta a incerteza, possuindo, portanto, função coordenadora (KIRZNER, 2007). Além disso, o empreendedor é de fundamental importância para geração de riqueza, não apenas dele, mas também dos agentes com que se relaciona. Trata daquele indivíduo que sacia vontades futuras ao estar "sempre alerta"10 a oportunidades inexploradas e preferências, visando um processo de descoberta de novos objetivos e meios para atingi-los. Representa um estado de aprendizado constante que melhora a eficiência alocativa através da aprendizagem. O papel desse conhecimento para os empreendedores é extremamente relevante, segundo a escola austríaca. Trata-se de um conhecimento evolutivo, tácito, prático (não científico), disperso, falível e limitado. Além disso, apresenta características dinâmicas, mutáveis, subjetivas e que melhoram com as instituições transmissoras, tais como: a propriedade privada, a moeda e os preços, sendo transmitido através do processo de mercado.

Kirzner (1997) coloca o agente empreendedor no centro desse processo, chegando a afirmar que concorrência e empreendedorismo coincidem e não existiriam um sem o outro. Com o conhecimento ampliado da realidade do mercado, o empreendedor tem que oferecer alternativas melhores do que as propostas pelos seus competidores para conseguir conquistar clientes e seguir com seu plano (BARBIERI, 2001). O autor concilia as noções de conhecimento subjetivo e realidades subjacentes, quando sugere que mercado tem justamente a função de descobrir o conhecimento ainda latente, de origem subjetiva, e baseado nas interpretações dos agentes (KIRZNER, 1992). Na verdade, o conhecimento dos agentes não é oferecido, mas a realidade subjacente é dada para o analista. Isso permite identificar claramente as oportunidades de lucro em relação às realidades subjacentes do mercado. As forças que moderam a ignorância são maiores que as que a geram, com base no alertness despertado pela oportunidade de lucro. $\mathrm{O}$ estado de alerta corrige o erro e torna-se também um elemento coordenador. $\mathrm{Ou}$ seja, mesmo o erro faz parte de um processo de coordenação mais amplo. Nesse sentido, as

${ }^{10}$ Estado de "alertness". 
atividades empresariais formariam uma tendência equilibradora através do seu processo de correção de erros.

Mas o que o estado de alerta do empreendedor se esforça para perceber e imaginar corretamente são (o que virá a ser) realidades futuras, e é o ganho potencial oferecido por essas realidades que "liga" o alerta empresarial. Segue-se, portanto, que o que virá a ser as realidades futuras estão de fato crucialmente envolvidas na formação da presciência empresarial e, portanto, das ações empresariais. É por essas razões que argumentaremos que o processo de equilíbrio posto em movimento pela atividade empresarial orientada para o lucro é, afinal, inspirado pelas realidades subjacentes. (KIRZNER, 1992, p. 27)

Na apreciação que Gianturco (2014) faz do empreendedorismo em Kirzner, fica patente que a fonte principal do lucro está relacionada à capacidade dos empresários anteciparem correta e simultaneamente o estado futuro do mercado. Se fosse possível para todos essa compreensão a priori, ninguém obteria nem lucro, nem prejuízo. Por essa razão, o autor observa que a teoria austríaca vai além da visão convencional do lucro como fonte de recompensa envolvendo os custos de uma iniciativa acrescida de um residual. Nessa equação, ele inclui de forma protagonista e central, a capacidade do empreendedor de descobrir onde estão as oportunidades como fonte de lucro. Essa consideração é igualmente evidenciada por Soto (2013) quando relembra o conceito de eficiência dinâmica, entendido como a competência de estimular a criatividade empreendedorial, no sentido da descoberta de oportunidades de lucro e a coordenação, no sentido de superar eventuais desajustes sociais. Cabe mencionar dois autores que enriquecem a discussão em seu dissenso com Kirzner quanto à teoria de processo de mercado e do papel do empreendedor respectivamente. O primeiro é o economista alemão Ludwig Lachmann (1906-1990). Enquanto Kirzner (1992) aposta que as forças atuantes no processo de mercado sejam predominantemente equilibradoras, Lachmann (1978) entendia que eram desequilibradoras. O processo de descoberta de Kirzner seria impossível do ponto de vista de Lachmann, dado que não é possível descobrir algo incógnito, desconhecido. As descobertas não atenuam as incertezas simplesmente porque são impossíveis de serem logradas. Sendo assim, a tendência de equilíbrio por descoberta não é uma força equilibradora. Não existiria aquele empreendedor excepcional e visionário, pois apenas a difusão do conhecimento faria esse papel.

A outra crítica sofrida por Kirzner foi do economista, historiador e filósofo político americano Murray Rothbard (1926-1995), quanto à questão do empreendedor "puro" (não capitalista) e do estado de alerta quanto à natureza das oportunidades a serem exploradas e seu processo de descoberta (ROTHBARD, 2011). Ainda que Kirzner insinuasse que o isolamento do agente empreendedor fosse no sentido teórico, visando apenas isolar a variável empreendedora para estudar sua essência e contribuições, ao mesmo tempo, explicita que o empreendedor não seria dono dos meios de produção e dos recursos (KIRZNER, 1997). Rothbard desaprova veementemente esse prisma, afirmando ser impossível separar a visão empreendedora da capitalista (ROTHBARD, 2011; GIANTURCO, 2014). Empreendedores não estariam apenas alertas ao ambiente e às mudanças, como Kirzner (1997) menciona, mas também constroem oportunidades por meio de seus recursos pessoais e da interação com outros agentes, com 
os quais eles fazem acordos e, com isso, transformam os seus recursos em novos meios e objetivos (SARASVATHY, 2008).

Em 1937, o economista britânico Ronald Coase (1910-2013), em seu seminal artigo "The Nature of the Firm" (COASE, 1937), tratou da questão da razão da existência das firmas, mais especificamente em seu propósito de operacionalizar e minimizar os custos de produção para operar no mercado. Muito embora a literatura econômica apresente diversas referências a respeito da teoria da firma, a Escola Austríaca dedicou pouca atenção às firmas e organizações, inclusive em relação aos seus mecanismos internos (MARTINS, 2016).

É justamente nessa lacuna que se enquadra o professor Peter Klein. O economista faz uma tentativa de abrir a denominada, "caixa preta" da firma, manipulada para transformar insumos em produtos (JENSEN; MECKLING, 2008), inclusive se apoiando em Kirzner (1966), na concepção de que os bens de capital não devem ser caracterizados em função de suas propriedades físicas, mas pela sua posição na estrutura de produção (FOSS et al., 2007). Klein (2015) procura mostrar como o cálculo econômico do empreendedor corrobora para lidar com a questão dos limites para o tamanho da firma.

O autor segue a ideia de Rothbard no que diz respeito ao empreendedor-capitalista e coloca o empreendedorismo e o cálculo econômico no centro de uma teoria da firma austríaca, com viés Misesiano (MARTINS, 2016). Na prática, Klein posiciona a ideia da firma entre a função empreendedora e a capitalista. Outro autor que influenciou Klein foi Cantillon, no que diz respeito ao conceito do empreendedor com julgamento.

A noção de empreendedorismo como julgamento implica uma ligação óbvia com a teoria da firma [...] A firma é definida como o empreendedor mais os ativos inalienáveis que possui, e que, portanto, controla em última instância. A teoria da firma torna-se, então, uma teoria de como o empreendedor arranja seus ativos de capital heterogêneos, que combinações de ativos tentará adquirir, quais decisões (imediatas) delegará aos subordinados, como proporcionará incentivos e utilizará o monitoramento para verificar se seus ativos são utilizados de forma consciente, com seus julgamentos. (KLEIN, 2015, p. 114)

O empreendedor em Klein deixa de ter uma conotação puramente praxeológica para assumir um papel ativo de conseguir ou organizar os bens de capital que possui, gerando lucro. O julgamento atua como instrumento avaliativo sobre o controle dos recursos, sempre interposto por um ambiente de incerteza na manutenção do empreendimento (BITTAR et al., 2014). Obviamente que o lucro é o resultado almejado, mas ao mesmo tempo, completamente incerto. São diversas as variáveis que influenciam na obtenção do lucro, o que acaba tornando sua consumação um grande desafio para os empreendedores. Entre os aspectos a serem considerados, destacam-se a própria natureza mutável da preferência dos consumidores, as características do mercado em que o negócio está inserido, a macro e a microeconomia, o conhecimento da competição, dos fornecedores, de novos entrantes, produtos substitutos, além do empenho e diligência que o empreendedor coloca em seu julgamento quanto às oportunidades que se avizinham.

De todos os autores mencionados, Klein é o que mais promove a inserção da temática do empreendedorismo como amálgama entre as teorias econômicas e de gestão, em especial no 
que tange a estratégia nas organizações (KLEIN, 2008b). O autor explora diversas ramificações a partir dessa tônica, como a da relação entre o empreendedorismo e a governança corporativa, fazendo uso da figura do empreendedor capitalista de Rothbard. Sob essa ótica, a firma poderia ser entendida de duas formas (KLEIN, 2015). A primeira é aquela baseada no empreendedorpromotor (MISES, 2010a), na qual o empreendedor deve comprar insumos no presente com preços conhecidos, visando a venda do produto final a preços incertos no futuro. A diferença geraria lucro ou prejuízo dependendo do grau de eficácia no manejo da incerteza.

O segundo formato é com base na visão do capitalista, do proprietário da firma, que por sua vez, delega atividades aos respectivos gestores. Partindo dessa premissa, a governança corporativa passa a ser a chave para maximização dos lucros a partir do arranjo de gestão feito pelos detentores do capital (KLEIN, 2015). Problemas podem surgir a partir dessa intersecção, dado que, como sugerido por Klein (2015), a liderança organizacional, ainda que crucial, não é necessariamente empreendedora. Mais ainda, como garantir que os interesses dos gestores não venham a sobrepujar os do capitalista? É o que Klein denomina problema do "agenteprincipal" (KLEIN, 2015, p. 68) e "julgamento derivado" (KLEIN, 2015, p. 137).

É a partir dessa inquietação que Klein desenvolve sua teoria austríaca para governança corporativa e enfatiza a importância da heterogeneidade do capital para teoria do empreendedorismo e da firma. Klein reconhece a necessidade de um maior engajamento dos gestores nas perspectivas de ações que agreguem valor à estratégia e ao negócio como um todo. Entre elas, cita a descentralização, a escolha ocupacional, elaboração de contratos e aprendizagem organizacional. Com efeito, esse esforço de empoderamento de gestores está diretamente ligado à agilidade nos negócios, como reportado a seguir.

\section{Agilidade Organizacional}

O empreendedorismo segue sendo um campo de contínua estruturação e evolução epistemológica, no qual o empreendedor é um dos possíveis prismas de análise (MACHADO; NASSIF, 2014). Não obstante, as próprias organizações constituem outro ângulo relevante. Em um cenário de mercado com tamanha liquidez de contingências, as organizações precisam se superar para poder continuar entregando seus produtos e serviços da maneira mais eficiente e com foco na experiência do cliente. Além disso, devem se destacar por inovar constantemente, criando tendências e antecipando demandas inexistentes no cenário avassalador e ao mesmo tempo inexorável da 4⿳亠丷a Revolução Industrial (DENNING, 2019; LEOPOLD, 2019; RODRIGUEZ; MOLINA, 2018; CHEN et al., 2016).

Paradoxalmente, a forma com que as organizações são conduzidas parece ter chegado ao limite de desgaste e as receitas utilizadas até então parecem ser parte do problema (LALOUX, 2017). A resposta para o desafio de sobreviver e florescer em um mundo reconhecidamente acelerado não parece estar no emprego de modelos tradicionais de gestão ou no uso da tecnologia pura e simplesmente (DENNING, 2019; CRICK, 2017). Por outro lado, é fato que algumas empresas conseguem um impacto desproporcionalmente maior em comparação com seus pares, exercendo influência direta no cotidiano de milhões de pessoas em função 
do emprego de novas técnicas organizacionais que alavancam sua inovação (ISMAIL et al., 2014). O segredo por trás do sucesso dessas organizações que primam por se tornarem tão flexíveis quanto o contexto imprevisível e mutável que se estabeleceu, florescendo em meio ao caos (ou fazendo uso dele), reside em um novo padrão de gestão denominado: agilidade organizacional.

A própria expressão "agilidade" pode induzir o incauto ao despautério de considerar que o termo se refere a fazer as coisas de maneira açodada, mas não é sobre isso que versa a agilidade. No seu aspecto mais amplo, que é o da aplicação nos negócios, a agilidade faz alusão a uma nova mentalidade de gestão, muito mais do que um método ou conjunto de ferramentas. Métodos são importantes, podem constituir vias para que se chegue à agilidade organizacional, mas não são seu propósito.

Para Meyer (2015, p. 10), agilidade é o desenvolvimento intencional de competências, capacidades e confiança para aprender, adaptar e inovar em contexto de mudança. Denning (2019, p. 34) sugere que a gestão ágil não trata de fazer mais trabalho em menos tempo, mas sim, de gerar mais valor com menos trabalho. Verstraete (2004) aventa que o nível de agilidade nos negócios envolve a latência entre o aparecimento de um evento externo e a implantação da mudança apropriada. Para Wadhwa e Rao (2003), agilidade nos negócios seria a habilidade de lidar com mudanças que são, em grande medida, imprevisíveis, com respostas mais inovadoras. Ramasesh et al. (2001) defendem que a agilidade é exploração bem sucedida de bases competitivas (velocidade, flexibilidade, inovação, proatividade, qualidade e lucratividade) por meio da integração de recursos reconfiguráveis e melhores práticas em um ambiente rico em conhecimento para fornecer produtos e serviços voltados para o cliente em um contexto de mudança.

Como se pode observar, as diferentes definições de agilidade convergem para a capacidade da organização lidar com mudanças imprevistas. Mais ainda, se ela é capaz de responder de maneira inovadora e não apenas pré-projetada. A origem da expressão é normalmente associada ao segmento de tecnologia da informação (TI), particularmente no que diz respeito ao desenvolvimento de software (DENNING, 2019; MEYER, 2015; MEKARKODE et al., 2004), mas seu sustentáculo remete aos princípios da produção enxuta ${ }^{11}$ ou do chamado Sistema de Produção Toyota12 (GHEZZI; CAVALLO, 2020; LEOPOLD, 2019; KHURANA, 2017; RIES, 2011). Ainda que as raízes da abordagem enxuta (lean) tenham sido inicialmente desenvolvidas por Taiichi Ohno (1912-1990) para Toyota, suas aplicações se estenderam a diversos outros segmentos de mercado (MALEYEFF, 2006). O significado do lean envolve a mudança pela qual uma organização cria valor para seus usuários e para a sociedade de forma geral, evidenciando questões como: foco no cliente, eliminação de desperdício, aprendizagem contínua, busca incessante pela qualidade, entre outros (BALLÉ et al., 2019).

Durante os anos 1990, uma reinterpretação do pensamento lean por especialistas de desenvolvimento de software foi motivada por uma miríade de desafios enfrentados por

${ }^{11}$ Lean Manufacturing: tradução livre.

${ }^{12}$ Toyota Production System (TPS): tradução livre. 
projetos de engenharia software que falhavam em atender às expectativas de usuários no que diz respeito à qualidade, prazo, orçamento, ou uma combinação dessas variáveis (THE STANDISH GROUP, 2016). Esse esforço culminou na elaboração ou refinamento de diversas práticas e metodologias, mas a consolidação dos métodos ágeis ocorreu a partir da elaboração de um documento intitulado "Manifesto Ágil", em fevereiro de 2001. O manifesto teve assinatura de dezessete expoentes em desenvolvimento de software, que declararam estar "descobrindo maneiras melhores de desenvolver software fazendo e ajudando outros a fazerem" (BECK et al., 2001). Os quatro valores abordados no manifesto sintetizam a agilidade no que diz respeito ao desenvolvimento de produtos: “(1) Indivíduos e interações entre eles mais que processos e ferramentas, (2) Software em funcionamento mais que documentação abrangente, (3) Colaboração com o cliente mais que negociação de contratos, (4) Responder a mudanças mais que seguir um plano" (BECK et al., 2001).

A partir do manifesto, a gama de práticas associadas à agilidade fez com que fossem criadas ou reestruturadas inúmeras instituições especializadas com o objetivo de fomentar a escalada ágil no desenvolvimento de produtos e na organização como um todo. O Quadro 2 traz algumas das principais instituições ligadas a esse propósito.

Quadro 2. Instituições promotoras da agilidade

\begin{tabular}{|l|l|}
\hline Instituição & Site \\
\hline Agile Business Consortium & www.agilebusiness.org \\
\hline Agile Institute & www.agileinstitute.com \\
\hline APMG International & www.apmg-international.com \\
\hline Business Agility Institute (BAI) & www.businessagility.institute \\
\hline International Consortium for Agile (ICAgile) & www.icagile.com \\
\hline International Project Management Association (IPMA) & www.ipma.world \\
\hline Kanban Institute & www.kanbaninstitute.com \\
\hline Project Management Institute (PMI) & www.pmi.org \\
\hline Scaled Agile Framework (SAFe) & www.scaledagileframework.com \\
\hline Scrum Alliance & www.scrumalliance.org \\
\hline Scrum.Org & www.srcum.org \\
\hline
\end{tabular}

Fonte: Autoria própria.

Com o desenrolar da primeira década do século XXI, as práticas ágeis tomaram um vulto ainda maior, formando o que se pode denominar de um novo paradigma gerencial (ANNOSI et al., 2020; RIGBY et al., 2020; DENNING, 2018; DUBEY, 2016; STENBECK, 2015; MEYER, 2015).

Desde então o movimento da agilidade se avolumou em inúmeras organizações ao redor do globo, passando a afetar e influenciar múltiplas áreas da organização e segmentos inteiros de mercado (STENCBECK, 2015; LEOPOLD, 2019; BALOG, 2020). Essa reorganização aspirando agilidade, normalmente, ocorre através de mudanças incrementais constantes ${ }^{13}$, que

\footnotetext{
${ }^{13} \mathrm{O}$ que no pensamento lean é conhecido como Kaizen, simbolizando um processo de melhoria contínua.
} 
propiciam aprendizado ao ambiente, com uma atitude mais compatível com o atual momento vivido pelas organizações.

Nesta conjuntura, o cliente passa a ser o centro de todas as ações e todo resto da cadeia de valor da organização passa a ser estruturada em função dessa lógica. Qualquer empecilho a esse racional deve ser eliminado. Nesse conjunto de possíveis impedimentos, fazem parte: a tecnologia envolvida, processos, burocracia, estrutura organizacional, hierarquia, sistemas de incentivo e medição, entre outros. É o que Sthephen Denning chamou de "lei do cliente" (DENNING, 2018, p. 71). Por mais paradoxal que possa parecer essa lista, por vezes, a tecnologia ou qualquer outro fator, pode ser usado como escusa, gerando fricção com o cliente ao invés de facilitar. Em outras palavras, a cadeia de valor da organização deve ser montada em função do cliente e não o oposto (DENNING, 2015). Ademais, a cadeia de valor tem que estar sempre sendo revisitada em busca de possíveis gargalos. Muitas atividades internas podem não agregar valor ao processo ou mesmo impedindo a criação de valor. Na agilidade, esse desperdício deve ser identificado e tratado de forma obsessiva e, de preferência, com a economia gerada sendo repassada para o cliente.

Só esse axioma, uma vez aplicado efetivamente, traria consigo um enorme potencial transformador no ambiente de negócios. Entretanto, os maiores desafios para adoção da agilidade estão relacionados à cultura organizacional no sentido da sua resistência à mudanças, além da falta de apoio, conhecimento e, consequentemente, patrocínio a iniciativas nesse sentido (GUEZZI; CAVALLO, 2020; VERSIONONE, 2020; CALIGIURI, 2013).

Fazer a mudança para o novo paradigma não é fácil. Uma coisa é aceitar intelectualmente que agregar valor aos clientes é o propósito de uma organização. Outra é pegar os objetivos, sistemas, processos, estruturas, valores, hábitos, atitudes e cultura de toda uma burocracia e transformar esse princípio intelectual em realidade (DENNING, 2018, p. 88).

Outro desafio importante é o ajuste fino entre o grau de burocracia ideal a ser adotado, na medida em que a agilidade nos negócios não combina com burocracia exagerada. Ainda que os princípios da burocracia façam parte da história da administração em função das suas características relacionadas à meritocracia, previsibilidade e planejamento, sua adequação se faz imperiosa. Considerando o paradigma da agilidade, uma organização regida por normas fixas, seguindo princípios hierárquicos e impessoais, se torna anacrônica. A maioria das pessoas que atua ainda através de sistemas burocráticos, acaba por se sentir desengajada de suas funções (RIGBY et al., 2020).

A essência da burocracia pode ser aplicável, ainda que com ressalvas (WEBER, 2004), em um mundo mais previsível em que se domine o que será produzido e como será produzido. A preocupação com a eficiência interna e aumento da produtividade, com ênfase nas tarefas e padronização dos métodos de produção induzia a um tipo de trabalho repetitivo que poderia ser depois supervisionado com uma liderança mais voltada a aspectos de comando e controle. Ocorre que com a complexidade do mundo atual, o mercado clama por inovações. Não basta ser criativo, é preciso gerar valor (RIGBY et al., 2020; BARCAUI, 2020; DENNING, 2018; DUBEY, 2016; STENBECK, 2015). Mais ainda, é preciso entender primeiro o que o cliente considera 
valor para depois ajudar a alcançá-lo. O conceito de valor é emancipado da tecnologia ou método utilizado ${ }^{14}$, sendo extremamente subjetivo a cada cliente. Mesmo no caso de serviços que atendem as massas, o consumidor demanda a sensação de exclusividade.

Como não existe fórmula predeterminada a ser seguida e como a natureza do trabalho mudou profundamente, não se trata mais de selecionar as melhores pessoas, treiná-las e depois controlar seu rendimento. É preciso uma nova forma de liderança baseada em inspiração, que privilegie o emocional, a colaboração e o trabalho em equipe (CALIGIURI, 2013), afinal as habilidades gerenciais são fundamentalmente comportamentais, não podendo ser atribuídas exclusivamente a fatores de personalidade e focadas em resultados apenas (WHETTEN; CAMERON, 2007).

Antigos modelos organizacionais extremamente hierarquizados e com uma disposição física de espaço como evidência de ostentação de poder, cedem espaço a layouts mais neutros, estruturas com menos níveis hierárquicos e mais horizontais em suas linhas de comunicação. A agilidade sugere que o desembaraço na tomada de decisão é fator diferencial nos negócios e que valorizar as pessoas e suas interações é chave para a manutenção da estratégia organizacional. Pequenas equipes multifuncionais com responsabilidades claras são montadas, a despeito da disposição departamental original de cada profissional. A esses times é outorgada liberdade com responsabilidade para o autogerenciamento, de tal modo que as lideranças emergem dentro do próprio grupo, em função da característica do que está sendo produzido, do momento e da maturidade da equipe. Essa consideração é importante porque a maior parte das tarefas conduzidas dentro das organizações é realizada por times e, inclusive, com a maioria das pessoas participando em mais de uma equipe (ADP RESEARCH, 2019).

Almeja-se um fluxo de trabalho, que promova não só o bem estar da equipe, mas também um ambiente colaborativo e de confiança. Não faz sentido em um ambiente ágil, gestores se cercarem de profissionais que lhe passem as exatas informações que desejam ouvir, mas que, na prática, se traduzem em falácias de resultados. Sobretudo, ainda serem recompensados por esse procedimento, incentivando sua repetição e condicionando o comportamento de todas as pessoas envolvidas nesse corrompido processo. Organizações que ainda operam assim deixam evidente a natureza patológica dessa conduta torpe e maculada.

A agilidade organizacional, ao contrário, prega a transparência de informações, ancorada por um ritmo sustentável de trabalho e uma certa liberdade de ação para desenvolvimento de produtos. As equipes funcionam em configuração de rede e as pessoas são alocadas de forma adjacente uma das outras, de forma que a comunicação passa a ocorrer de maneira mais fluida e "osmótica"15. Obviamente que essa autonomia deve estar alinhada com os objetivos estratégicos da empresa e o sistema de incentivos também deve ser modificado para acomodar realizações da equipe e não individuais, como de costume (BARCAUI, 2020).

\footnotetext{
${ }^{14}$ Considerando-se a licitude do mesmo.

${ }^{15}$ Analogia ao processo de osmose utilizada por Cockburn (2006) e que se refere a campos de energia que naturalmente irradiam das pessoas quando são arranjadas de maneira próxima. Segundo o autor, com profissionais afastados, a troca é muito pequena, já com estreita proximidade, todos obtêm benefícios.
} 
Ainda que o fundamento se apresente animador, é preciso lembrar que produtos e serviços não são planejados e engendrados de forma isolada por times independentes entre si. O desempenho da organização não é nunca a soma dos times separadamente, mas o produto de sua interação (ACKOFF, 1999). Equipes dependem umas das outras e a agilidade é criada quando as interações entre elas são igualmente ágeis (LEOPOLD, 2019). Deveras, talvez seja esse um dos maiores desafios da agilidade: sua escalada organizacional (LEHN, 2018; DENNING, 2016).

Esse novo desenho da gestão que visa inovação contínua como meio de sustentabilidade e geração de lucro precisa necessariamente de diversidade, capacidade de antecipação e uso da intuição como mola propulsora de sucesso. Inovação não aparece do vácuo, mas de um ambiente que promova o despudor da imaginação, que seja mais tolerante a riscos e que esteja aberto à experimentação, que é uma das bases da agilidade. Em um ambiente de constante inovação, nem todo produto iniciado é continuado. Nesse percurso, o esforço não é garantia de sucesso no mercado, mas aqueles que passam pelo crivo da apreciação positiva, são naturalmente recompensados pelo ato da escolha de seus consumidores (CONSTANTINO, 2009). O ponto de partida deve ser entender que problema será resolvido com a solução proposta (LEOPOLD, 2019).

Uma vez aceitas essas premissas, os gestores necessitam criar ou adaptar seu modelo de negócio para abarcar esse novo arquétipo gerencial. Ocorre que não existe um caminho único a ser seguido por todas as organizações que querem se tornar ágeis (DENNING, 2019; CALIGIURI, 2013). Visto que as organizações são sistemas complexos, o que significa que as variáveis interagem de maneira diferente em ambientes distintos (RIGBY et al., 2020), cada trajetória em direção à agilidade se torna extremamente idiossincrática ao longo do seu desenvolvimento. A chamada "transformação ágil" é muito mais um percurso do que propriamente um marco ou uma data específica de conquista (DENNING, 2019). Quanto mais a agilidade estiver presente, mais rapidamente a organização poderá responder às demandas de adequação. $\mathrm{O}$ processo de inovação contínua não é apenas na geração de produtos e serviços em si, mas também na própria prática de gestão e no modelo de negócio a ser adotado ou ajustado.

Para Osterwalder e Pigneur (2010), um modelo de negócio descreve o racional de como uma organização cria, entrega e captura valor. Porém, esse ciclo sofre com uma profunda e insidiosa transformação uma vez que o ambiente atual é de incerteza perene, provocando similarmente uma mudança de comportamento nos agentes empreendedores. Quando as circunstâncias de mercado eram claras e mais tangíveis, era não só praxe, como recomendado, que grandes planos de negócio contendo análises profundas de público-alvo, estratégia de marketing, oportunidades, ameaças, forças, fraquezas, análise de viabilidade, cronograma, entre outras considerações, fossem produzidos.

Todavia, atualmente, no âmbito da agilidade, planos como esses correm o risco de se tornarem obsoletos antes mesmo de estarem completos em suas definições preditivas. Não se trata de abandonar o planejamento, mas sim, de uma contenda saudável entre planejar e adaptar. O planejamento somente preditivo cede espaço a um outro formato de planejamento mais contínuo e adaptativo, com entregas incrementais em ciclos mais curtos, porém assíduos, 
e sempre com base no feedback do cliente, visando experimentação no sentido estrito do empirismo. Hipóteses são continuamente testadas em relação aos resultados no mundo real, gerando aprendizagem contínua.

Em um mundo que não oferece respostas prontas, saber fazer as perguntas corretas pode fazer toda diferença. A mudança de mentalidade envolve deixar de lado a dependência extrema de informações prontas, para redução da incerteza através da aprendizagem evolutiva. Mas para tanto é preciso que a organização como um todo esteja empenhada e tenha disposição de aprender e, eventualmente, desaprender, para poder recomeçar. O ciclo construir-mediraprender (GHEZZI; CAVALLO; RIES, 2020; 2011) envolve a transformação de uma ideia em produtos ou serviços consumíveis, avaliando a reação de clientes e, a partir dela, optando por perseverar no mesmo produto ou modificá-lo. Conforme colocado por Agarwal et al. (2007), o processo de obtenção desse conhecimento quando feito de maneira constante e orgânica, combinados com a ação empreendedora, resultam na criação de novos projetos, heterogeneidade no desempenho e subsequente crescimento.

\section{Análise e Discussão}

Feita a revisão do tema empreendedorismo pelo viés austríaco e também dos fundamentos da agilidade nos negócios, é possível testemunhar aspectos equivalentes que em grande parte ratificam o entendimento do mercado como um sistema complexo, em que seus componentes ou agentes interagem de forma imprevisível entre si. Dessa forma, as consequências desse tipo de sistema não representam a soma simples de suas partes isoladas, mas sim, do resultado da interação não-linear entre elas. Dito de outra forma, temos uma infinidade de possíveis combinações de agentes atuando de forma ativa em um fluxo contínuo de experiências que mudam de forma constante no arcabouço de profunda incerteza. No conjunto desses agentes fazem parte os empreendedores, as organizações, seus concorrentes, os clientes, fornecedores, o estado, entre outros stakeholders ${ }^{16}$.

A relação e o convívio entre essas partes ocorrem das mais variadas formas, sob o efeito de um tempo contínuo completamente heterogêneo e oscilante. Todos esses aspectos instituem um gabarito de complexidade extremamente elevado, permeado de riscos e que demanda por soluções de mercado inovadoras, com foco no valor sendo gerado para consumidores, como constatação de sua soberania.

O postulado da primazia do cliente talvez seja o ponto principal de anuência em toda evolução histórica do empreendedorismo na Escola Austríaca desde sua fundação, sendo devidamente reiterado nos dias de hoje a partir do movimento ágil. Ainda que as abordagens tenham se modificado e sido reinterpretadas ao longo do tempo, são perceptíveis as relações de influência exercidas por cada um dos autores naqueles que os sucederam. A Figura 3 a seguir representa essas relações de influência entre os distintos expoentes do empreendedorismo. ${ }^{16} \mathrm{O}$ termo aqui sendo utilizado segundo a definição clássica de Freeman et al. (2004, p.13): "qualquer grupo ou indivíduo
que afeta ou é afetado pelo alcance dos objetivos da firma". 


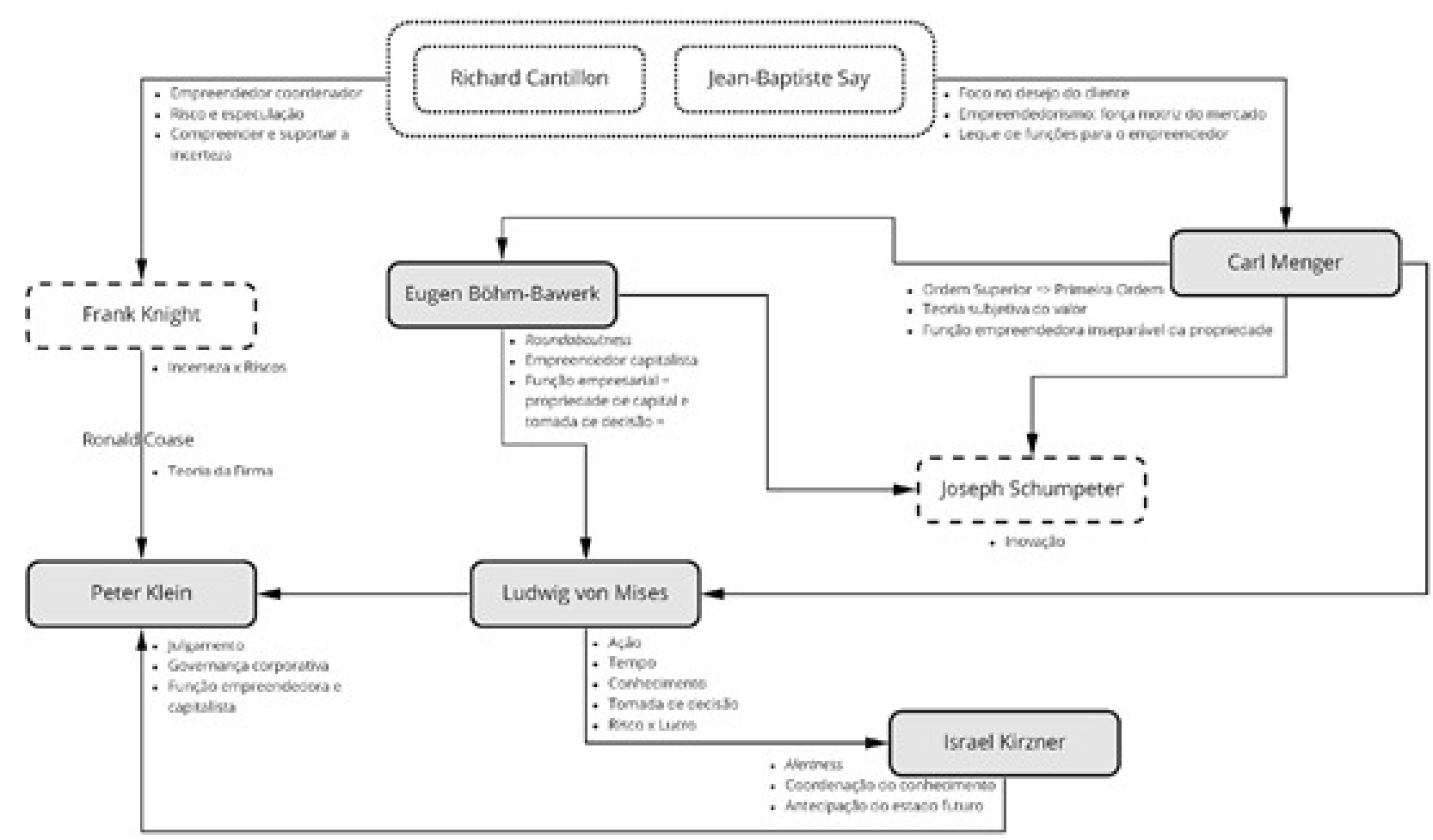

Figura 3. Influências entre expoentes do tema empreendedorismo

Fonte: Autoria própria.

Os autores em linha pontilhada não são austríacos (Say, Cantillon, Knight) ou não são membros da Escola Austríaca propriamente dita (Schumpeter), todavia, sua contribuição foi assaz relevante para a compreensão e desenvolvimento do tema dentro dos objetivos desse trabalho de pesquisa.

As setas representam as relações de influências, refletindo as alíneas exploradas por cada um dos autores, nas quais, em muitos casos, denotavam um refinamento da teoria do seu antecessor ou, em outros, o pavimento para que novas contribuições pudessem ser desenvolvidas, como no caso de Böhm-Bawerk em Schumpeter ou de Mises em Kirzner. Algumas influências ocorreram de maneira indireta como as de Menger em Schumpeter e outras de maneira mais direta, como a de Cantillon em Knight a respeito do conceito de incerteza e da especulação, que depois se desenvolve através da teoria da firma de Coase, chegando a Klein, que tem inspiração também em Mises e Kirzner.

Desde sua gênese em Menger, é patente como as questões relativas ao valor subjetivo e à tomada de decisão e adaptação, são recursivamente abordadas, ainda que com hermenêuticas particulares, como no caso do "empreendedor com julgamento" de Klein. Outro tema que chama atenção na revisão da bibliografia dos autores, seja de forma tácita ou explícita, é a questão da aprendizagem amplamente explorada em Mises, Kirzner e Klein. Os conceitos da agilidade condizem com a maioria desses pontos abordados pelos autores estudados, principalmente, quando se esmeram em colocar o cliente no epicentro das ações da empresa, em detrimento de estruturas hierárquicas, processos ou outro tipo de bloqueio. Reconhecem também que 
qualquer avaliação a ser feita deve partir da inevitabilidade da inserção do empreendedorismo em um ambiente de completa e absoluta incerteza, em função das características do próprio mercado e de riscos a serem assumidos, derivados dessas incertezas, conforme observado por Cantillon e Knight.

Contudo, dois pontos merecem atenção do empreendedor no sentido não só de amortecer os desafios gerados pela incerteza, mas também de servir como diferencial na equação da sua sobrevivência, manutenção e crescimento no mercado. O primeiro é a valorização das pessoas, uma vez que empreendimentos são desenvolvidos através de pessoas, para pessoas, sem as quais nenhum empreendimento faria sentido. O outro é a tentativa de fazer o melhor uso do conhecimento disponível, de forma que o leque de decisões a ser tomado ocorra da maneira mais embasada possível e com maior probabilidade de acerto.

Feito o enquadramento do ambiente no qual os empreendedores (e demais agentes) estão inseridos, optou-se por uma divisão dos princípios da agilidade organizacional em três dimensões para fins da análise associativa: mercado, pessoas e valor. Em cada dimensão foram elencados quatro pontos de diligência, com base na literatura revista (Quadro 3).

Quadro 3. Dimensões da agilidade nos negócios

\begin{tabular}{|l|c|c|}
\hline Mercado & Pessoas & Valor \\
\hline Adaptação & Colaboração & Transparência \\
\hline Inovação & Trabalho em Equipe & Foco no Cliente \\
\hline Aprendizagem Contínua & Ritmo Sustentável & Eliminação de Desperdício \\
\hline Experimentação & Autogerenciamento & Qualidade \\
\hline
\end{tabular}

Fonte: Autoria própria.

Uma vez compilados esses pontos de aplicação em cada dimensão, procurou-se proceder a uma associação, na medida do possível, com os autores austríacos do empreendedorismo que foram estudados. Esse pesquisador entende que em muitos casos, alguns autores poderiam estar listados em mais de uma dimensão, dado que sua tratativa foi transversal aos diversos temas tratados.

Por outro lado, algumas outras questões trazidas pela agilidade, notadamente na dimensão "pessoas" não foram pontualmente tratadas dentro da temática do empreendedorismo da Escola Austríaca. Pelo menos não da forma preconizada pela agilidade organizacional.

A Figura 4 a seguir, representa um esforço de síntese do empreendedorismo pela Escola Austríaca, com a lente da agilidade nos negócios, considerando as três dimensões constituídas e emolduradas em um contexto de incerteza e riscos, nos quais as pessoas e o conhecimento formam importantes pilares de sustentação para o empreendedor. 


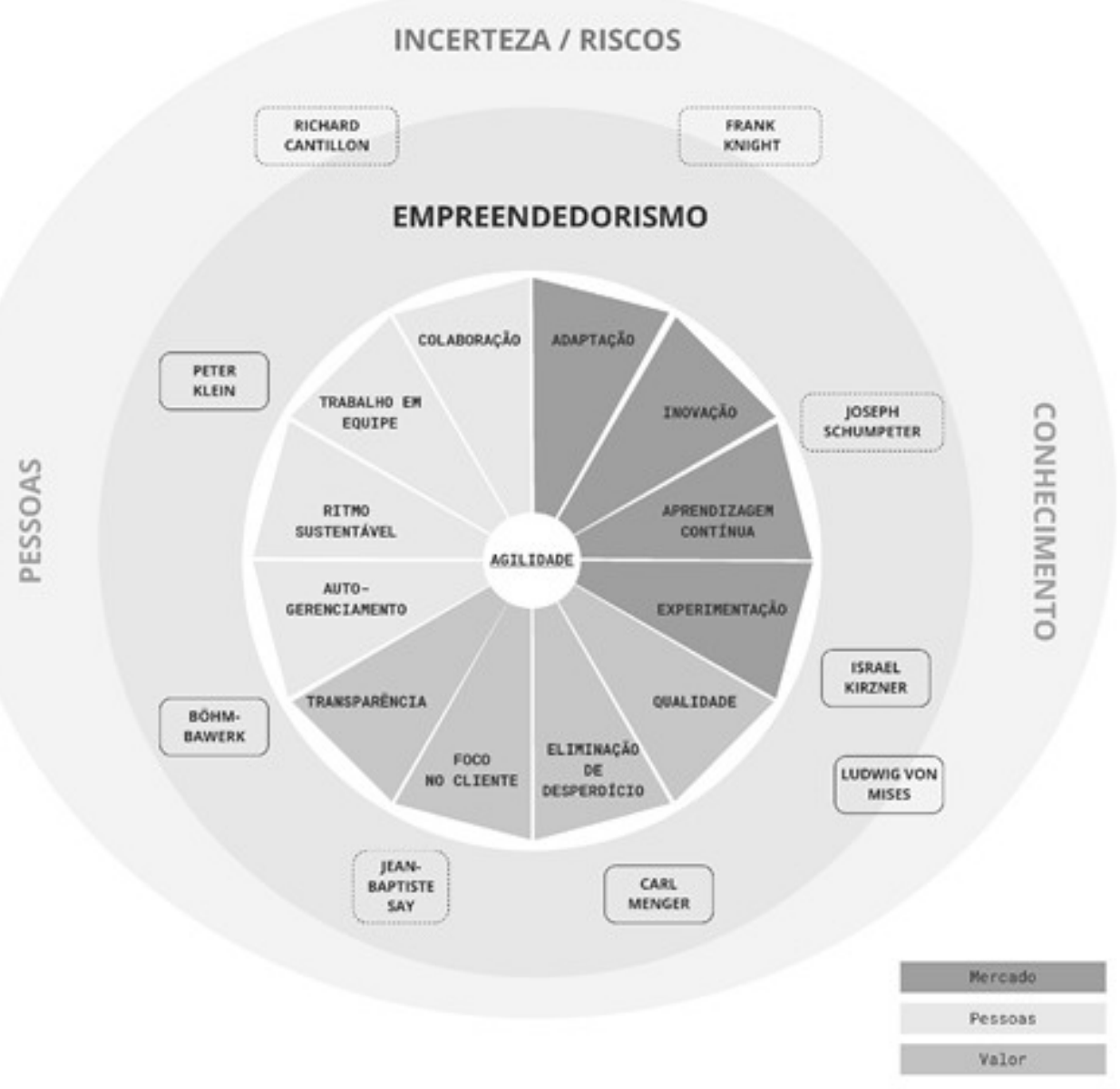

Figura 4. Representação da síntese entre empreendedorismo na EA e agilidade

Fonte: Autoria própria.

Na dimensão relativa ao valor, a coordenação de recursos produtivos proposta por Say se adequa à eliminação de desperdícios e ao foco na qualidade trazidos pela agilidade. Já a antecipação de necessidades e a noção incontestável de valor subjetivo de Menger são aderentes à questão da transparência e do foco no cliente, em que pese que seja tarefa minimamente árdua, quiçá infrutífera em certas circunstâncias, avaliar as preferências de clientes em função das diversas conjunturas que se apresentam.

A dimensão inerente ao mercado sugere que a competição resulta na descoberta de dados que jamais seriam conhecidos sem a atividade competitiva. Novas tecnologias e novos conhecimentos estão sempre sendo gerados em função de diferentes demandas da sociedade ou mesmo de maneira espontânea. A realidade é mutante e como os agentes e as relações entre eles mudam, sempre influenciados pela sua história e transmutação de expectativas, o mercado como um todo acaba sendo um processo no qual a economia se acomoda da melhor forma. Trata-se de um exercício ininterrupto de adaptação inerente às ciências humanas. O que se tem é um constante ajuste às contínuas mudanças do mercado em condições específicas de tempo e local. Essa consideração corrobora outro aspecto de complementaridade entre os autores 
austríacos e a agilidade: o humilde reconhecimento da incerteza e dos riscos onipresentes e a necessidade constante de adaptação presentes em Schumpeter, Kirzner e no próprio Mises.

A experimentação adotada pela agilidade é uma forma de mitigar esses riscos, mas não deixa de configurar uma ação por parte do empreendedor, em um determinado momento do tempo, fazendo uso do conhecimento adquirido até então. Assim sendo, o processo contínuo de aprendizagem estabelece outra intersecção importante entre os austríacos e a agilidade organizacional.

Mesmo a tentativa de maximização dos lucros do negócio pressupõe um estado contínuo e incessante de estudo, uma atitude sempre antenada e uma tomada de riscos frequente, porque é impossível saber ao certo o custo de oportunidade das opções em que não se apostou. Funciona quase como um processo Darwiniano aplicado ao mercado, que acaba selecionando as melhores atitudes empreendedoras entre aquelas que destroem valor. Sob esse ponto de vista, é possível entender porque inovar se torna tão relevante e também porque a busca pelo novo, leva em consideração não só o prisma da criatividade, mas principalmente o potencial de valor gerado e a utilidade da inovação.

Dito isso, chama a atenção um detalhe que poderia se constituir em um ponto de maior conciliação entre os autores austríacos estudados e a agilidade organizacional. Trata-se da legítima preocupação da agilidade com a vertente de pessoas no contexto da organização. A exceção é a perspectiva praxeológica de Mises, que explica que as pessoas, por vontade própria, não só absorvem, como promovem um sistema de cooperação, no qual o mercado serve como bússola para promoção do bem estar do indivíduo e dos demais (MISES, 2010a). Esse ponto de vista coaduna com a dimensão pessoas, principalmente nos tópicos relativos à colaboração e autogerenciamento. Quanto aos demais autores, ainda que Böhm-Bawerk tenha trazido a questão do controle dos meios de produção e que Klein aborde a perspectiva da governança corporativa, da ética e do empoderamento, alguns aspectos considerados chave na perspectiva da agilidade não são abordados de forma direta, tais como: o trabalho em rede, a interdependência entre times, e o ritmo sustentável de trabalho, que não aparecem com a mesma conotação ou grau de relevância.

Feita essa apreciação, duas outras ressalvas também são necessárias. A primeira é que se deve dar o devido desconto aos diferentes períodos do tempo em que cada autor austríaco fez sua contribuição, uma vez que abstrações e conceitos não são isentos da devida contextualização histórica. A segunda observação é que o corte feito por esse trabalho de investigação circunscreveu uma temática específica: empreendedorismo; não enfocando outros aspectos da economia austríaca que poderiam, eventualmente, estabelecer outras bases comparativas em relação às pessoas no contexto da gestão.

Por fim, algumas das dúvidas dos primeiros autores estudados permanecem mais atuais do que nunca na agilidade. Particularmente o debate entre o grau de planejamento a ser adotado em contraste com o nível de adaptação a ser implementado. Planejar é importante, mas fazêlo em excesso, em um mundo onde a mudança é a maior constante, soa como um sofisma. $\mathrm{O}$ ponto ótimo dessa equação, se existir, é ainda uma das maiores questões a serem resolvidas pelas organizações ágeis. Talvez a frase que melhor represente essa polêmica seja a de Hayek 
(1995, p. 108), quando coloca que a "curiosa tarefa da economia consiste em demonstrar aos homens quão pouco eles conhecem a respeito do que imaginam poder planejar".

\section{Considerações Finais}

O objetivo deste artigo foi examinar os conceitos de empreendedorismo na Escola Austríaca sob a lente da agilidade. Após a análise associativa realizada, comprovou-se que a anastomose insinuada no título não apenas se faz presente como também harmoniza os princípios austríacos do empreendedorismo com a maioria dos aspectos da agilidade organizacional. Em certos pontos analisados, é como se os autores austríacos estivessem predizendo temáticas trazidas muito tempo depois pelo movimento da agilidade e legitimados pelo mercado, como observado na síntese realizada. As razões para esse fenômeno podem ser advindas do exercício da mais pura lógica econômica austríaca ou fruto da ordem espontânea de Hayek, mas o fato é que os preceitos básicos de adaptação constante, foco no cliente e criação de valor seguem mais vivos do que nunca.

Essa nova era ágil que já poderia ser interpretada como uma releitura do movimento lean, aparece também como reconhecimento ou confirmação da importância dos postulados austríacos quanto ao empreendedorismo. Salvo a dimensão relativa às pessoas, que demanda uma postura diferenciada por parte da liderança das organizações, as demais dimensões estiveram presentes nas reflexões dos autores austríacos, cada um com uma determinada peculiaridade, em função da época em que foi argumentado.

Do ponto de vista dos empreendedores, o desafio seguirá vultoso. Não basta entender o novo paradigma, é preciso se submeter com efeito a ele. Quanto às organizações, a mudança cultural demandada não é trivial. Se sujeitar genuinamente ao reinado do cliente requer uma transformação profunda, um envolvimento holístico de toda empresa e, porventura, mudanças na própria cultura organizacional. O modo ou protótipo, se é que existe, de como os empreendedores e as organizações conseguem esse intento, talvez, sirva de incentivo para futuros trabalhos de pesquisa.

\section{Referências}

ABREU, Mariana. Empreendedor “austríaco” vs. Empreendedor schumpeteriano. Instituto Ludwig von Mises, 2012. Disponível em: https://www.mises.org.br/Article.aspx?id=1195. Acesso em: $10 \mathrm{dez} 2020$.

ACKOFF, Russel. A Lifetime of Systems Thinking. The System Thinker, v. 10, n. 5, p. 1-4, 1999.

ADP Research 2019. The Global Study of Engagement - Technical Report ADP Research Institute, 2019. Disponível em: https://www.adp.com/media/adp/ResourceHub/pdf/ADPRI/ADPRI0102_2018_Engagement_ Study_Technical_Report_RELEASE\%20READY.ashx. Acesso em: 21 dez 2020.

AGARWAL, R.; AUDRETSCH, D.; SARKAR, M. The process of creative construction: knowledge spillovers, entrepreneurship and economic growth. Strategic Entrepreneurship Journal, v. 1, n. 3-4, p. 263-287, 2007.

BECK, Kent et al.. The manifesto for agile software development. Publicado em 13 de fevereiro de 2001. Disponível em: http://www.agilemanifesto.org. Acesso em: 03 jan 2021. 
ALDRICH, Howard. The Emergence of Entrepreneurship as an Academic Field: a personal essay on institutional entrepreneurship. Research Policy, v. 41, n. 7, p. 1240-1248, 2012.

ALVAREZ, Sharon; BARNEY, Jay. How entrepreneurs organize firms under conditions of uncertainty. Journal of Management, v. 31, n. 5, p. 776-793, 2005.

ANNOSI. Maria; MARTINI, Antonella; BRUNETTA, Federica; MARCHEGIANI, Lucia. Learning in an agile setting: a multilevel research study on the evolution of organizational routines. Journal of Business Research, v. 110, p. 554-566, 2020.

ANTONACOPOULOU, Elena. Organizational Learning for and with VUCA: Learning Leadership Revisited. Teoria e Prática Em Administração, v. 8, n. 2, p. 10-32, 2018.

BALLÉ, Michael; JONES, Daniel; CHAIZE, Jacques; FIUME, Orest. A Estratégia Lean. Porto Alegre: Bookman, 2019.

BALOG, Katalin. The concept and competitiveness of agile organization in the fourth industrial revolution's drift. Strategic Management, v. 25, n. 3, p. 10-32, 2020.

BARBIERI, Fabio. O processo de mercado na escola austríaca moderna (Dissertação de Mestrado). Faculdade de Economia, Administração e Contabilidade, Universidade de São Paulo, SP, Brasil, 2001.

BARBIERI, Fabio. A Economia do Intervencionismo. São Paulo: Instituto Mises Brasil, 2013.

BARCAUI, André. Agilidade. In: COSTA, Helio (Org). Gestão Empresarial. E-book Kindle, 2020.

BITTAR, Fernando; BASTOS, Livia; MOREIRA, Vivian. Reflexões sobre o Empreendedorismo: uma análise crítica na perspectiva da economia das nações. Revista de Administração da UFSM, v. 7, n. 1, p. 65-80, 2014.

BÖHM-BAWERK, Eugen. Capital and Interest. South Holland: Libertarian Press, 1959.

BÖHM-BAWERK, Eugen. Teoria positiva do capital. São Paulo, Nova Cultural, 1986.

BRANDA, Domingos. O Pai Fundador da Economia Moderna: Richard Cantillon. Instituto Ludwig von Mises, 2011. Disponível em: https://www.mises.org.br/Article.aspx?id=938. Acesso em: 13 dez 2020.

BRUE, Stanley. História do Pensamento Econômico. São Paulo: Thomson Learning, 2006.

BRUYAT, Chistian; JULIEN, Pierre-André. Defining the field of research in entrepreneurship. Journal of Business Venturing, p. 16, n. 2, p. 165-180, 2001.

CALIGIURI, Paula. Developing culturally agile global business leaders. Organizational Dynamics, v. 42, n. 3, p. 175-182, 2013.

CANTILLON, Richard. Ensaio sobre a Natureza do Comércio em Geral. Curitiba: Segesta, 2002.

CARVALHO, André; NETO, João Machado. A economia monetária de Cantillon e o debate moderno entre ortodoxia e heterodoxia. Economia e Sociedade, v. 28, n. 1, p. 31-51, 2019.

CHEN, Roger; RAVICHANDAR, Ramya; PROCTOR, Don. Managing the transition to the new agile business and product development model: Lessons from Cisco Systems. Business Horizons, v. 59, n. 6, p. 635-644, 2016.

COASE, Ronald. The nature of the firm. Economica, v. 4, n. 16, p. 386-405, 1937.

COCKBURN, Alistair. Agile software development: The cooperative game. Boston: Addison-Wesley, 2006. 
CONSTANTINO, Rodrigo. A Economia do Individuo: o legado da escola austríaca. Versão Kindle. São Paulo: Instituto Ludwig Von Mises Brasil, 2009.

CRICK, Charles.; CHEW, Eng. Business processes in the agile organization: a socio-technical perspective. Software and Systems Modeling, v. 16, n. 3, p. 631-648, 2017.

DENNING, Stephen. The Age of Agile. Amacom: Edição do Kindle, 2018.

DENNING, Stephen. How to make the whole organization "Agile". Strategy \& Leadership, v. 44, n. 4, p. 10-17, 2016.

DENNING, Stephen. The Quest for Genuine Business Agility. Strategy \& Leadership, v. 48, n. 1, p. 21-28, 2019.

DUBEY, Manoj. Developing an Agile Business Excellence Model for Organizational Sustainability. Global Business and Organizational Excellence, v. 35, n. 2, p. 60-71, 2016.

FILION, Louis Jacques. Empreendedorismo: empreendedores e proprietários -gerentes de pequenos negócios. RAUSP: Revista de Administração USP, v. 34, n. 2, p. 5-28, 1999.

FOSS, Nicolai; KLEIN, Peter. Entrepreneurship and the economic theory of the firm: any gains from trade? In: AGARWAL, Rajshree; ALVAREZ, Sharon; SORENSON, Olav. Handbook of entrepreneurship research: disciplinary perspectives. Springer: Dordrecht, 2005.

FOSS, Nicolai; FOSS, Kirsten; KLEIN, P.; KLEIN, Sandra. The entrepreneurial organization of heterogeneous Capital. Journal of Management Studies, v. 44, n. 7, p. 1165-1186, 2007.

FREEMAN, Edward; WICKS, Andrew; PARMAR, Bidham. Stakeholder: Theory and the corporate objective revisited. Organizational Science, v. 15, n. 3, p. 364-369, 2004.

GHEZZI, Antonio; CAVALLO, Angelo. Agile Business Model Innovation in Digital Entrepreneurship: Lean Startup Approaches. Journal of Business Research, v. 110, p. 519-537, 2020.

GIANTURCO, Adriano. O empreendedorismo de Israel Kirzner. São Paulo: Instituto Ludwig Von Mises Brasil, 2014.

GLITZ, Eduardo; MAISONNAVE, Marcelo; ENGLERT, Pedro. Empreendedores. São Paulo: Gente, 2019.

GRAY, David. Pesquisa no Mundo Real. Porto Alegre: Penso, 2012.

HAYEK, Friedrich. The Use of Knowledge in Society. American Economic Review, v. 35, n. 4, p.519-530, 1945.

HAYEK, Friedrich. A Arrogância Fatal - Os Erros do Socialismo. São Paulo: Ortiz, 1995.

HAYEK, Friedrich. Economics and Knowledge. Economica. Auburn: Mises Institute, 2005. Disponível em: https://mises.org/library/economics-and-knowledge. Acesso em: 15 dez 2020.

HISRICH, Robert; PETERS, Michael; SHEPHERD, Dean. Empreendedorismo. Porto Alegre: Bookman, 2009.

IORIO, Ubiratan. Ação, Tempo e Conhecimento: A Escola Austríaca de Economia. São Paulo: Instituto Ludwig Von Mises Brasil, 2011.

IORIO, Ubiratan. O Pensamento de Jean-Baptista Say sobre as principais questões da Economia. Instituto Ludwig von Mises, 2013. Disponível em: https://www.mises.org.br/Article.aspx?id=1679. Acesso em: 02 dez 2020.

IORIO, Ubiratan. Richard Cantillon (168?-1734) e o Início da Economia Moderna. Instituto Ludwig von Mises, 2014a. Recuperado de: https://www.mises.org.br/Article.aspx?id=1813. Acesso em: $19 \mathrm{dez} 2020$. 
IORIO, Ubiratan. Cantillon, os ciclos econômicos e a não-neutralidade da moeda. Instituto Ludwig von Mises, 2014b. Recuperado de: https://www.mises.org.br/Article.aspx?id=1819. Acesso em: 02 dez 2020.

ISMAIL, Salim; MALONE, Michael; GEEST, Yuri. Exponential Organizations. New York: Diversion Books, 2014.

JENSEN, Michel; MECKLING, William. Teoria da Firma: Comportamento dos Administradores, Custos de Agência e Estrutura de Propriedade. Revista de Administração de Empresas (RAE), v. 48, n. 2, p. 87-125, 2008.

JULIEN, Pierre-André. Empreendedorismo regional e economia do conhecimento. São Paulo: Saraiva, 2010.

KHURANA, Subinder. In a VUCA World, all Businesses are Startups. Medium 19, 2017. Disponível em: https:// medium.com/@subinder/in-a-vuca-world-all-businesses-are-startups-c13a4563fc0f. Acesso em: 23 nov 2020.

KIRZNER, Israel. The Meaning of Market Process - Essays in the development of the modern Austrian Economics. London: Routledge, 1992.

KIRZNER, Israel. Entrepreneurial Discovery and the Competitive Market Process: an Austrian Approach. Journal of Economic Literature, v. 35, n. 1, p. 60-85, 1997.

KIRZNER, Israel. Principles of Economics. Alabama: Ludwig von Mises Institute, 2007.

KLEIN, Peter. Menger, o Revolucionário. Instituto Ludwig von Mises, 2008a. Disponível em: https://www. mises.org.br/article/85/menger-o-revolucionario. Acesso em: 02 dez 2020.

KLEIN, Peter. Opportunity discovery, entrepreneurial action, and economic organization. Strategic Entrepreneurship Journal, v. 2, n. 3, p. 175-190, 2008b.

KLEIN, Peter. O Capitalista e o Empreendedor - Ensaios sobre Organizações e Mercados. São Paulo: Instituto Mises Brasil, 2015.

KNIGHT, Frank. Risk, uncertainty and profit. New York: August M. Kelley, 1921.

LACHMANN, Ludwig. Capital \& Its Structure. Alabama: Ludwig von Mises Institute, 2007.

LACHMANN, Ludwig. Capital, Expectations, and the Market process: essay on the theory of the Market economy. The Online library of Liberty, 1977. Disponível em: http://files.libertyfund.org/files/97/0721_Bk.pdf. Acesso em: 28 nov 2020.

LACHMANN, Ludwig. Capital and Its Structure. Kansas: Sheed, Andrews and McMeel, 1978.

LALOUX, Frederic. Reinventando as Organizações. Curitiba: Doyen, 2017.

LANDSTRÖM, Hans; LOHRKE, Franz. Historical Foundations of Entrepreneurship Research. Great Britain: Edward Elgar Publishing, 2010.

LEHN, Kenneth. Corporate Governance, Agility and Survival. International Journal of the Economics of Business, v. 25, n. 1, p. 65-72, 2018.

LEOPOLD, Klaus. Rethinking Agile - why agile teams have nothing to do with business agility. Vienna: Leanability, 2019.

LYNSKEY, Michael; SEIICHIRO, Yonekura. Entrepreneurship and Organization: the role of the entrepreneur in organizational innovation. Oxford: Oxford University Press, 2002.

MARTINS Yasmmin. O Capitalista e o Empreendedor: Ensaios Sobre Organizações e Mercados. Mises: Interdisciplinary Journal of Philosophy Law and Economics, v. 4, n. 1, p. 299-302, 2016. 
MACHADO, Hilka.; NASSIF, Vânia. Replica - Empreendedores: Reflexões sobre Concepções Históricas e Contemporâneas. RAC, v. 18, n. 6, p. 892-899, 2014.

MALEYEFF, John. Exploration of internal service systems using lean principles. Management Decision, $\mathrm{v}$. 44, n. 5, 2006.

MARTES, Ana Cristina. Weber e Schumpeter: A ação econômica do empreendedor. Revista de Economia Política, v. 30, n. 2, 2010.

MCCAFFREY, Matthew. Mises and Schumpeter: Friendly Rivals?. Publicado pelo Mises Institute, 2014. Disponível em: https://mises.org/library/mises-and-schumpeter-friendly-rivals. Acesso em: 15 dez 2020.

MEHMOOD, Tariq et al. Schumpeterian Entrepreneurship Theory: Evolution and Relevance. Academy of Entrepreneurship Journal, v. 25, n. 4, p. 1-10, 2019.

MELARKODE, Ajit; FROM-POULSEN, Mark; WARNAKULASURIYA, Sugath. Delivery Agility through IT. Strategy Review, v. 15, n. 3, p. 45-50, 2004.

MENGER, Carl. Liberalismo: Princípios da Economia Política. Lebooks Editora. Edição do Kindle, 2017.

MEYER, Pamela. The Agile Shift. New York: Bibliomotion, 2015.

MISES, Ludwig von. Ação Humana - Um tratado de economia. São Paulo: Instituto Ludwig Von Mises Brasil, 2010a.

MISES, Ludwig von. Intervencionismo: uma análise econômica. São Paulo: Instituto Ludwig Von Mises Brasil, 2010b.

MISES, Ludwig von. A natureza econômica dos lucros e prejuízos. Instituto Ludwig von Mises, 2012. Disponível em: https://mises.org.br/ArticlePrint.aspx?id=1374. Acesso em: $11 \mathrm{dez} 2020$.

MURPHY, Robert. A Origem do Dinheiro e de seu Valor. Instituto Ludwig von Mises, 2010. Disponível em: https://www.mises.org.br/Article.aspx?id=209. Acesso em: 17 dez 2020.

OSTERWALDER, Alexander; PIGNEUR, Yves. Business Model Generation - a Handbook for Visionaries, Game Changers, and Challengers. New Jersey: John Wiley, 2010.

PRIKLADNICKI, Rafael; LASSENIUS, Casper; CARVER, Jeffrey. Trends in Agile: Business Agility. IEEE Software, v. 37, n. 1, p. 78-80, 2020.

RAMASESH, Ranga; SHAILESH, Kulkarni; JAYAKUMAR, Maliyakal. Agility in Manufacturing Systems: an exploratory modeling framework and simulation. Integrated manufacturing systems, v. 12, n. 6, p. 534-548, 2001.

ROTHBARD, Murray. O Mito Adam Smith. Instituto Ludwig von Mises, 2009. Disponível em: https://www. mises.org.br/ArticlePrint.aspx?id=434. Acesso em: 30 nov 2020.

ROTHBARD, Murray. A natureza do empreendedor: o problema com a teoria de Hayek e Kirzner. Instituto Ludwig von Mises, 2011. Disponível em: https://www.mises.org.br/Article.aspx?id=958. Acesso em: 02 dez 2020.

RIES, Eric. A Startup Enxuta. Rio de Janeiro: GMT Editores, 2011.

RIGBY, Darrell; ELK, Sarah; BEREZ, Steve. Doing Agile Right - Transformation without Cahos. Boston: HBR Press, 2020.

SALERNO, Joseph. Menger's causal-realist analysis in modern economy. The Review of Austrian Economics, v. 23, n. 1, p. 1-16, 2008. 
SARASVATHY, Saras. Effectuation elements of entrepreneurial expertise. Great Britain: Edward Elgar Publishing, 2008.

SCHUMPETER, Joseph. Capitalismo, Socialismo e Democracia. Rio de Janeiro: Editora Fundo de Cultura, 1961.

SOTO, Jesús. Empreendedorismo, Eficiência Dinâmica e Ética. Instituto Ludwig von Mises, 2013. Disponível em: https://www.mises.org.br/Article.aspx?id=1373. Acesso em: 29 nov 2020.

STENBECK, John. Agile Almanac. Spokane: GR8PM, 2015.

THE STANDISH GROUP. Chaos Report. Boston: The Standish Group, 2016.

THORNTON, Mark. Richard Cantillon: The Origin of Economic Theory. In: The Great Austrian Economists. Alabama: Mises Institute, 1999.

THORNTON, Mark. Cantillon on the Cause of the Business Cycle. Alabama: Mises Institute. The Quarterly Journal of Austrian Economics, v. 93, 2006.

TOMETICH, Patricia. Empreendedorismo - um conceito impreciso. Revista Estratégia \& Desenvolvimento, v. 4, n. 1, 2020.

VERSTRAETE, Christopher. Planning for the unexpected [business agility]. Manufacturing Engineer, v. 83, n. 3, p. 18-21, 2004.

VERSIONONE 2020. The $14^{\text {th }}$ State of Agile Report. Ditigal AI, 2020. Disponível em: https://stateofagile.com/\#. Acesso em: 02 dez 2020.

WADHWA, S; RAO, K. Flexibility and Agility for Enterprise Synchronization: Knowledge and Innovation Management Towards “Flexagility. Studies in Informatics and Control, v. 12, n. 2, p. 111-128, 2003.

WEBER, Max. Economia e Sociedade. Brasília: UnB, 2004.

WHETTEN, David; CAMERON, Kim. Developing Management Skills. New Jersey: Pearson Prentice Hall, 2007.

WHITEMAN, Wayne. Training and education army officers for the 21st Century: Implications for the United States. Publicado pelo USAWC Strategy Research Project em 1998. Disponível em: https://apps.dtic.mil/dtic/tr/ fulltext/u2/a345812.pdf. Acesso em: 29 nov 2020.

RECEBIDO: 02 DE FEVEREIRO DE 2020.

APROVADO: 15 DE FEVEREIRO DE 2020. 